
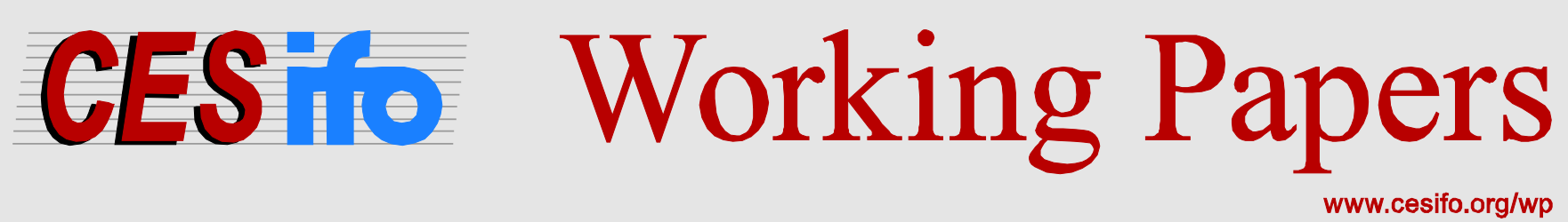

\title{
Cooperation on Climate-Change Mitigation
}

\author{
Charles F. Mason \\ Stephen Polasky \\ Nori Tarui
}

\author{
CESIFO WORKING PAPER NO. 5698 \\ CATEGORY 10: ENERGY AND CLIMATE ECONOMICS \\ JANUARY 2016
}

Presented at CESifo Area Conference on Energy and Climate Economics, October 2015

An electronic version of the paper may be downloaded

- from the SSRN website: $\quad$ www.SSRN.com

- from the RePEc website: $\quad$ www.RePEc.org

- from the CESifo website: www.CESifo-group.org/wp 


\title{
Cooperation on Climate-Change Mitigation
}

\begin{abstract}
We model countries' choice of greenhouse gas (GHG) emissions as a dynamic game. Emissions generate immediate benefits to the emitting country but also increase atmospheric GHG concentrations that negatively affect present and future welfare of all countries. Because there are no international institutions capable of enforcing environmental agreements on sovereign nations, we analyze self-enforcing climate-change treaties that are supportable as subgame perfect equilibria. In simulations based on current conditions, we explore the structure of a selfenforcing agreement that achieves efficient climate change policy.
\end{abstract}

JEL-codes: Q540, C730.

Keywords: international agreements, climate change, differential games.

Charles F. Mason

Department of Economics and Finance

University of Wyoming

1000 E. University Avenue

USA - 82071 Laramie, Wyoming

bambuzlr@uwyo.edu

Stephen Polasky

Department of Applied Economics

University of Minnesota

USA - St. Paul, MN 55108

polasky@umn.edu
Nori Tarui

Department of Economics

University of Hawaii at Manoa \& UHERO

USA - Honolulu, HI 96822

nori@hawaii.edu

December 2015

The authors thank Stephen Salant, Akihiko Yanase, and the seminar participants at the University of Hawaii, the ASSA Meetings, CESifo area conference, University of California Riverside, Doshisha, European Association of Environmental and Resource Economists, Japan Economic Association Meeting, Hitotsubashi, Tokyo Tech, Tokyo, Tsukuba, Kobe, Keio University, University of Venice and the Occasional Workshop on Environmental and Resource Economics. The authors are responsible for any remaining errors. 


\section{Introduction}

Climate change is the central environmental concern of our time. There is a large scientific literature warning of the dangers of the failure to address emissions of greenhouse gases and continuing with business-as-usual (IPCC 2014, MA 2005). The Intergovernmental Panel on Climate Change (IPCC) concluded that "Continued emission of greenhouse gases will cause further warming and long-lasting changes in all components of the climate system, increasing the likelihood of severe, pervasive and irreversible impacts for people and ecosystems" (IPCC 2014, p. 56). As a result, the need to find a mutually agreeable strategy to mitigate GHG emissions "is becoming increasingly urgent" (Condon and Sinha, 2013 p. 50).

Climate change, however, is particularly difficult to address precisely because it is a global environmental problem (Barrett 2008). Global environmental problems require concerted action by numerous sovereign countries. However, national sovereignty limits the effectiveness of international agreements because they cannot force a country to do things that are not in the country's national self-interest. An international environmental agreement has to be "selfenforcing," that is, designed so that it is in the self-interest of each country to abide by the agreement. But designing self-enforcing agreements is problematic given the nature of global public goods. The self-interest of each country is best served by having other countries bear the cost of addressing the problem while free-riding on these efforts.

These problems are evident in efforts to negotiate an international agreement on climate change. Starting in 1995 countries have gathered annually at the annual Conference of Parties under the U.N. Framework Convention on Climate Change to negotiate an international climate change agreement. Two significant agreements have come from these meetings: the Kyoto Protocol in 1997, and the Paris Agreement in 2015. Emissions reductions under the Kyoto 
Protocol were small relative to the size of reductions necessary to avoid potentially dangerous climate change. Even so, many countries that agreed to binding emissions caps under the Kyoto Protocol exceeded their caps for the 2008-2012 period. There were no effective sanctions for violating emissions caps. The Paris Agreement on Climate Change assembled pledges to reduce greenhouse gas emissions from "Intended Nationally Determined Contributions" submitted by countries. While an important step forward, the sum of these pledges still falls far short of meeting the stated objective of the Paris Agreement to prevent more than a $2 \mathrm{C}$ increase in mean global temperature. The Paris Agreement is silent about enforcement mechanisms and there is no guarantee that countries will abide by their pledges.

In this paper, we take a different approach to the problem of designing a self-enforcing international environmental agreement for climate change. We use a dynamic game-theoretic model that accounts for both the immediate benefits of economic activity that leads to GHG emissions and the long-term damages from a build-up of atmospheric concentrations of GHGs (stock pollutant). In each period, each country chooses its level of economic activity. Current period direct benefits for a country are a concave function of its economic activity in that period. Atmospheric concentrations increase with emissions of GHG and decline with the decay of existing concentrations. We model current period damages to a country as a convex function of the atmospheric GHG concentration in that period. To support an international climate change agreement we use a strategy with a two-part punishment for deviations (Abreu 1988). Each country initially chooses emissions that generate an efficient outcome (cooperative strategy). Each country continues to play the cooperative strategy as long as all other countries do so. If a country deviates from the cooperative strategy, all countries then invoke a two-part punishment strategy. In the first phase, countries inflict harsh punishment on the deviating country by 
requiring it to curtail emissions while other countries expand emissions. In the second phase, all countries return to playing the cooperative strategy. We design the two-part punishment scheme to be subgame perfect. The punishment scheme is sufficiently severe so that it deters cheating from the cooperative strategy. The punishment scheme is also designed so that it is in the selfinterest of all countries to carry out the punishment if called upon to do so. The punishment scheme is robust against renegotiation because, by construction, countries revert to the efficient emission control path upon completion of the first punishment phase.

We identify conditions in which the two-part punishment strategy we propose can support the efficient outcome as a subgame perfect equilibrium, i.e., where cooperation can be achieved through a self-enforcing international environmental agreement. Though such conditions are necessarily complicated for dynamic games with nonlinear payoff functions, we exploit several properties of the game to simplify the analysis. We provide a simulation model to illustrate when it is possible for a self-enforcing agreement to support an efficient outcome. We also parameterize the simulation model to mimic current conditions to show whether a selfenforcing agreement that achieves efficient climate change policy is likely to be possible. We find that whether the two-part punishment strategy leads to a self-enforcing efficient policy depends non-monotonically on the discount factor. While sufficiently small discount factors do not support an efficient outcome for the standard reason that the threat of future punishment is insufficient to deter the current benefit from cheating, sufficiently large discount factors may also fail to support an efficient outcome. Dutta (1995b) found that monotonicity regarding the discount factor - an implication of the folk theorem for repeated games - does not carry over to dynamic games. Our finding is consistent with this general result for dynamic games. We also find non-monotonicity regarding the marginal benefits and costs of GHG emission reduction. 
The two-part punishment strategy does not support a self-enforcing efficient policy when the slope of the marginal benefits of GHG emission is too large or too small relative to the slope of the marginal abatement cost. Our linear-quadratic example illustrates that these non-linear relationships are relevant over the range of values of key parameters - discount factor, elasticity of marginal utility, marginal benefits and costs of GHG emission reduction — that are used in previous numerical studies on climate change. Our dynamic-game analysis also demonstrates that the treaty may become supportable as the atmospheric concentration of GHG becomes sufficiently large while the treaty is not supportable at lower concentration levels.

Our model builds on several prior dynamic-game models applied to climate change agreements (Dockner et al., 1996; Dutta and Radner 2004, 2006a, 2006b, 2009). ${ }^{1}$ A general theme in these earlier papers is the identification of conditions under which cooperative equilibrium can be supported as a subgame perfect equilibrium through the use of a trigger strategy where a defection induces perennial reversion to a less attractive regime (i.e., once punishment begins it continues forever). A legitimate criticism of such strategies is that they are not robust against renegotiation once a country's deviation triggers punishment because the countries can do far better by restarting an agreement. By contrast, the two-part punishment strategy used in our model concentrates punishment up front followed by a reversion to the cooperative strategy. ${ }^{2}$. These papers also rely on stark linearity assumptions. While this provides considerable simplification to the analyses, they connote important departures from

\footnotetext{
${ }^{1}$ Dockner et al. consider a problem where payoffs are linear in the control variable, and where players use a grim trigger strategy (i.e., one with permanent punishment). Dutta and Radner (2004, 2006a, 2006b, 2009) assume linear damages. In Dutta and Radner (2004), the control variable is the emission factor (ratio of emissions to energy use); changing this variable is costly. They sketch examples where an efficient outcome is possible. Dutta and Radner (2006a) provides an extension using technology choice as the control variable. Technology choice influences the emission factor, and changing the control variable is costly. Dutta and Radner (2006b) allow for an evolving population. Dutta and Radner (2009) allow for asymmetric players.

${ }^{2}$ Our structure is also more compatible with the nature of actual treaties, as most international sanctions are temporary in nature (Hufbauer et al. 1985).
} 
reality. A number of researchers have argued that the impacts of climate change related damages will be nonlinearly related to GHG concentrations (Broecker, 1997; IPCC 2007; Schlenker et al. 2006; Schlenker and Roberts 2006). Dockner et al. (1996) allow for non-linear damages, but assume linear benefits from emissions. There is compelling evidence that marginal abatement costs (the negative of the marginal benefits of GHG emissions) are highly nonlinear (see, e.g. Nordhaus and Boyer 2000). Our analysis allows for both non-linear damages and non-linear flow payoffs. We find that the degree of nonlinearity in both benefits and damages plays a significant role in the ability to support an efficient self-enforcing international agreement on climate change.

Dutta (1995b), Polasky et al. (2006), and Tarui et al. (2008) analyze the use of a two-part punishment scheme to support efficient use of a common property renewable resource. While use of a common property resource has similarities to the climate change problem, climate change damages are potentially unbounded while those in a commons problem are not, as a player can simply opt of the commons problem and still get a reservation payoff).

Other related work includes papers that have applied static or repeated games (Barrett 2003, Chander and Tulkens 1995, Finus 2001) or have included the dynamics of GHG stock in a game-theoretic model (Bosello et al. 2003, de Zeeuw 2008, Eyckmans and Tulkens 2002, Rubio and Ulph 2007), to analyze the stability of international environmental agreements. ${ }^{3}$ Battaglini and Harstad (2015) and Harstad $(2012,2014)$ analyze incentives to invest in new, green technology. These new technologies aid in reducing emissions, by lowering the 'bliss point' level of emissions. Players write contracts that commit the negotiators to a sequence of emission levels. All these papers skirt questions of credibility, as they typically assume that treaty

\footnotetext{
${ }^{3}$ An international environmental agreement is stable when no country in the agreement can improve its payoff by dropping out of the agreement, and no country outside the agreement can improve its payoff by joining.
} 
member countries cooperate fully with the agreement even though cheating may improve a treaty member's welfare. ${ }^{4,5}$

In section 2, we describe assumptions of the model, the treaty design, and a few properties of the game that simplify the conditions under which the treaty yields a subgame perfect equilibrium. Section 3 analyzes conditions under which the two-part punishment strategy is a subgame perfect equilibrium using an example with quadratic functions. In Section 4, we choose the parameter values of the quadratic functions based on previous climate-change models to illustrate whether these conditions are likely to hold in reality. We conclude the paper in Section 5 .

\section{Basic model}

\subsection{Assumptions}

In each period, $t=0,1, \ldots$, each country, $i=1, \ldots, N$, chooses a GHG emission level, $x_{i t}$, $0 \leq x_{i t} \leq \bar{x}_{i}<\infty$, where $\bar{x}_{i}$ is the maximum feasible emission level for country $i$. The transition of the atmospheric GHG stock, S, is given by

$$
S_{t+1}=g\left(S_{t}, X_{t}\right)=\underline{S}+\lambda\left(S_{t}-\underline{S}\right)+\beta X_{t}
$$

\footnotetext{
${ }^{4}$ For example, Harstad (2012, p. 1528) says: "Rather than taking a stand on the countries' ability to commit, I derive the equilibrium contract as a function of this ability." Nordhaus and Yang (1996) investigate a dynamic game but assume that countries adopt open-loop strategies (where countries commit to future emissions at the outset of the game), which implies their equilibria tend not to be subgame perfect. Martin et al. (2003), Mäler and de Zeeuw (1998), and Yang (2003) study a dynamic game allowing for closed-loop strategies, but without including the role of punishment for potential defectors; that omission limits the ability to achieve efficient outcomes and overcome freerider problems.

${ }^{5}$ A large literature analyzes efficient climate change policy without consideration of the game-theoretic aspects of implementing and enforcing an international agreement; see Aldy et al. 2010 and Tol 2009 for recent summaries. The release of the Stern Review (Stern et al. 2006) ignited a new round of debate about efficient climate change policy, particularly the degree and the timing of emissions reductions (e.g., Dasgupta 2007, Mendelsohn 2007, Nordhaus 2007a and 2007b, Stern 2008, Stern and Taylor 2007, Tol and Yohe 2006, Weitzman 2007, Yohe et al. 2007, Garnaut 2008). While this literature provides important context to benefit and damage functions it is not directly relevant to the implementation and enforcement of an international agreement.
} 
where $X_{t} \equiv \sum_{i} x_{i t}, 1-\lambda$ represents the natural rate of decay of GHG per period $(0 \leq \lambda<1), \underline{S}$ is the natural equilibrium level of GHG stocks (the level prior to the industrial revolution), and $\beta$ is a conversion factor from emissions to atmospheric concentrations. Let $x_{-i t}$ be a vector of emissions by all countries other than $i$ and let $X_{-i t} \equiv \sum_{j \neq i} x_{j t}$, the total emissions by all countries other than $i$.

Let $\pi_{i}\left(x_{i t}, S_{t}\right)$ denote the payoff to country $i$ in period $t$ with emissions $x_{i t}$ when the GHG stock is $S_{t}$. We assume that this payoff equals the economic benefit from emissions, $B_{i}$, which is a function of its own emissions, minus climate damage, $D_{i}$, which is a function of the current GHG stock:

$$
\pi_{i}\left(x_{i t}, S_{t}\right)=B_{i}\left(x_{i t}\right)-D_{i}\left(S_{t}\right)
$$

We assume that $B_{i}$ is a strictly concave function with $B_{i}(0)=0$, that it has a unique maximum $x_{i}^{b}>0$, and that $B_{i}^{\prime}(x)>0$ for all $x \in\left(0, x_{i}^{b}\right)$. We call $x_{i}^{b}$ the "myopic business-as-usual" (myopic BAU) emission level of country $i$. This level of emissions maximizes current benefits from emissions without taking into account the damages associated with contributions to the stock of GHGs. We assume the damage function is increasing and convex in the GHG stock, $D_{i}{ }^{\prime}>0, D_{i}{ }^{\prime \prime}>0$

All countries use (common) one-period discount factor $\delta \in(0,1)$; this discount factor incorporates the growth rate of benefits and damages (see section 4.1 for further discussion). To focus the analysis, we abstract from issues of uncertainty, i.e. we assume that each country has complete information and that each country observes the history of GHG stock evolution and all countries' previous emissions. 


\subsection{Efficient solution}

The efficient emissions path solves the problem.

$$
\max \sum_{t=0}^{\infty} \delta^{t} \sum_{i} \pi_{i}\left(x_{i t}, S_{t}\right)
$$

s.t. $S_{t+1}=g\left(S_{t}, x_{t}\right)$ for $t=0,1, \ldots$ given $S_{0}$.

The solution to this problem generates a sequence of emissions $\left\{x_{t}^{*}\right\}_{t=0}^{\infty}$ where $x_{t}^{*}=\left\{x_{i t}^{*}\right\}_{i=1}^{N}$. The corresponding value function solves the functional equation. In what follows, we suppress time subscripts to simplify notation. The dynamic programming solution for this problem solves:

$$
\begin{gathered}
V(S)=\max _{x} \sum_{i} \pi_{i}\left(x_{i}, S\right)+\delta V\left(S^{\prime}\right) \\
\text { s.t. } \quad S^{\prime}=g(S, x) .
\end{gathered}
$$

We assume the solution is interior. The efficient emission profile given $S$, $x^{*}(S)=\left\{x_{1}^{*}(S), x_{2}^{*}(S), \ldots, x_{N}^{*}(S)\right\}$, satisfies:

$$
\frac{\partial \pi_{i}\left(x_{i}^{*}(S), S\right)}{\partial x_{i}}+\delta V^{\prime}\left(g\left(S, X^{*}(S)\right)\right) \beta=0
$$

for all $i$. The first term represents the marginal benefit of emissions in country $i$ while the second term is the discounted present value of the future stream of marginal damages in all countries from the next period. Thus, under the efficient allocation, the marginal abatement costs of all countries in the same period are equal, and equal to the shadow value of the stock.

The unique steady state $S^{*}$ satisfies:

$$
\frac{\partial \pi_{i}\left(x_{i}^{*}\left(S^{*}\right), S^{*}\right)}{\partial x_{i}}+\frac{\delta \beta}{1-\delta \lambda} \frac{\partial \sum_{j} \pi_{j}\left(x_{j}^{*}(S), S\right)}{\partial S}=0 .
$$


If the initial stock $S_{0}<S^{*}$, the stock increases monotonically to the steady state $S^{*}$; henceforth, we assume $S_{0}<S^{*}$. In what follows, we describe a strategy profile that supports $x^{*}$ as a subgame perfect equilibrium.

\subsection{A strategy profile to support an efficient solution}

Consider the following strategy profile $\phi^{*}$ with two-part punishment. ${ }^{6}$

\section{Strategy profile $\phi^{*}$}

- Phase I: Countries play $x^{*}(S)=\left\{x_{1}^{*}(S), x_{2}^{*}(S), \ldots, x_{N}^{*}(S)\right\}$. If any country $j$ chooses $x_{j} \neq x_{j}^{*}$, with resulting stock $S^{\prime}$, then go to Phase $\mathrm{II}_{j}\left(S^{\prime}\right)$ in the next period. Otherwise repeat Phase I in the next period.

- Phase $\mathrm{II}_{j}\left(S^{\prime}\right)$ : Countries play $x^{j}=\left(x_{1}^{j}, \ldots, x_{i}^{j}, \ldots, x_{N}^{j}\right)$ for $T$ periods. If a country $k$ deviates with resulting stock $S^{\prime \prime}$, go to Phase $\operatorname{II}_{k}\left(S^{\prime \prime}\right)$ in the next period. Otherwise go back to Phase I after $T$ periods.

The idea of the punishment strategy $x^{j}$ is to have country $j$ (that cheated in the previous period) choose low emissions for $T$ periods while the other countries choose high emissions. The punishment for country $j$ in Phase $\mathrm{II}_{j}$ works in two ways, one through its own low emissions (and hence low benefits during Phase II) and the other through increases in its future stream of damages due to an increase in the other countries' emissions during Phase II. The sanction is temporary, and countries resume cooperation once the sanction is complete. Under some parameter values and with appropriately specified punishment $\left\{x^{j}\right\}$, no country has an incentive

\footnotetext{
${ }^{6}$ The design of the two-part punishment scheme to support cooperation is similar to those discussed in Abreu (1988).
} 
to cheat, and if some country does cheat, all countries have an incentive to carry out the sanction. We now turn to a discussion of the condition under which $\phi^{*}$ is a subgame perfect equilibrium.

\subsection{Sufficient conditions for efficient sustainability}

Let $V_{j}^{C}(S, \mathrm{I})$ be country $j$ 's present value of payoffs given $\phi^{*}$ with cooperation in the current period, and $V_{j}^{D}(S, \mathrm{I})$ be country $j$ 's present value of payoffs given $\phi^{*}$ with the maximum payoff upon deviation in Phase I given current stock $S$. Similarly, let $V_{j}^{C}\left(S, \mathrm{II}_{i}\right), V_{j}^{D}\left(S, \mathrm{II}_{i}\right)$ be $j$ 's present value of payoffs upon cooperation and an optimal deviation starting in Phase $\mathrm{II}_{i}$ given stock $S$. The strategy profile involving cooperation and a two-part punishment scheme is a subgame perfect equilibrium if the following conditions are satisfied for all $j, j=1, \ldots, N$ :

Condition (1) Country $j$ has no incentive to deviate in phase I: $V_{j}^{C}(S, \mathrm{I}) \geq V_{j}^{D}(S, \mathrm{I})$;

Condition (2) Country $j$ has no incentive to deviate in phase $\mathrm{II}_{j}: V_{j}^{C}\left(S, \mathrm{II}_{j}\right) \geq V_{j}^{D}\left(S, \mathrm{II}_{j}\right)$; and

Condition (3) Country $j$ has no incentive to deviate in phase $\mathrm{II}_{k}$ for all $k \neq j$ :

$$
V_{j}^{C}\left(S, \mathrm{II}_{k}\right) \geq V_{j}^{D}\left(S, \mathrm{II}_{k}\right)
$$

for all possible stock levels given initial stock $S_{0}$. Because each player's flow payoff is bounded from above and the discount rate is positive, the principle of optimality for discounted dynamic programming applies to this game. Hence, in order to prove that $\phi^{*}$ is subgame perfect, it is sufficient to show that any one-shot deviation cannot be payoff-improving for any player (Fudenberg and Tirole 1991). As this is a dynamic game, we need to verify that no player has an incentive to deviate from the prescribed strategy in any phase and under any possible stock 
level. $^{7}$

Let $x_{i}^{D}(S)$ be the optimal deviation that maximizes country i's payoff upon deviation in either phase I or II. Under the reasonable assumption that $x_{i}^{D}$ exceeds the efficient emission level, it turns out that the three sufficient conditions can be reduced to one, namely condition (2). (Proofs of all propositions are presented in the appendix.)

Proposition 1 Suppose the punishment phase lasts one period, $T=1, x_{j}^{j} \equiv z \geq 0$ is independent of the post-deviation stock level, $x_{j}^{D}(S)>x_{j}^{*}(S)$, and $\sum_{i} x_{i}^{j}(S)=X^{*}(S)$ given any $S$. Then condition (2) implies conditions (1) and (3).

Proposition 1 shows that it is sufficient to evaluate condition (2) for a particular form of the twopart punishment scheme where the country that has deviated emits a fixed level $z$ and where other countries' emissions are designed so that combined emissions equal the efficient level given the post-deviation stock. While this strategy need not be optimal, focusing our discussion on this strategy greatly simplifies the task of verifying the existence of a strategy profile that yields a subgame perfect equilibrium. The next result shows that strategy profiles with multiple period punishments can be evaluated in a similar fashion.

Proposition 2 Countryj has no incentive to deviate in any period during phase $I_{j}$ if it has no incentive to deviate in the first period in phase $I I_{j}$.

Proposition 2 extends Proposition 1 to punishment strategies with multiple periods of

\footnotetext{
${ }^{7}$ See Dutta (1995a) for a similar analysis in a dynamic game context.
} 
punishment. Since country $j$ may cheat in any period during Phase IIj in this context, the concern is that there are now many conditions to check. The proposition shows that it is sufficient to check condition (2) for the first period of Phase IIj.

Finally, we note that there is an upper bound on the GHG stock because combined emissions are nonnegative and bounded by the maximum feasible level $\bar{X} \equiv \sum_{i} \bar{x}_{i}$, the feasible stock levels cannot exceed some level $\bar{S}$, which satisfies

$$
\begin{aligned}
& \bar{S}=\underline{S}+\lambda(\bar{S}-\underline{S})+\beta \bar{X} \\
& \bar{S}=\underline{S}+\frac{\beta \bar{X}}{1-\lambda}
\end{aligned} .
$$

Because there is an upper bound on stock, there are at most three candidate values for stock that could yield maximal deviation gains during phase II. If gains are monotonic in stock, the argmax is either the lowest possible value ${ }^{8}$ or the largest possible value. If gains are non-monotonic, then either there is an interior maximum (in which case the relevant stock value is that value which delivers the interior maximum) or there is an interior minimum, in which case the argmax is one of the two corners. In any event, it becomes a simple matter to check that deviation gains in phase $\mathrm{II}_{\mathrm{j}}$ are never positive for any country $j$.

When $\phi^{*}$ is not a subgame perfect equilibrium, there may be another strategy profile that supports the efficient as a subgame perfect equilibrium outcome. A punishment is most effective as deterrence against over-emitting if it induces the over-emitter's worst perfect equilibrium payoff. Though a punishment that invokes the worst perfect equilibrium supports cooperation under the widest range of parameter values, finding the worst perfect equilibrium is quite

\footnotetext{
${ }^{8}$ Certainly pollution stocks cannot be negative. Plausibly, there is a subsistence level of economic activity (that induces an associated subsistence level of emissions). Any country emitting less than that amount for an indefinite period of time would preclude its survival (though it might be able to survive for short periods, as during a punishment phase). If so, the lower bound on stock is strictly positive, and conceivably equal to the initial value.
} 
complicated in our model and so we do not attempt to solve for the worst perfect equilibrium.

Previous dynamic game studies analyzed cooperation with worst perfect equilibria punishment in the context of common- property resource use (Dutta 1995b, Polasky et al. 2006). With common-property resource use, the worst perfect equilibrium payoff is defined by the outside option for a resource user - the payoff that player would receive if they stopped using the resource. With climate change, a country cannot opt out: they will suffer damages as a function of the state of the climate regardless of whether or not they cooperate with the international agreement. With linear damage functions, Dutta and Radner (2004) find that the worst perfect equilibria take a simple form (constant emissions by all countries). With nonlinear damage functions, the worst perfect equilibria is more complicated because it depends nonlinearly on the state variable.

\section{An illustrative example for climate change with homogeneous countries}

In this section, we explore the practical ability of such a strategy to support a self-enforcing international agreement that achieves an efficient outcome using parameter values employed in economic studies on climate change. To facilitate this inquiry we adopt a linear-quadratic specification (Newell and Pizer 2003 Karp and Zhang 2006, 2009). Though simplistic, linearquadratic models have several advantages. They ease the burden of computing equilibria of dynamic games, and they are "simple to calibrate and easy to interpret, making it possible to understand the effect of assumptions about parameters" (Karp and Zhang 2006). For now, we also impose homogeneity across countries' payoff function; this assumption is relaxed below.

The flow payoff function we adopt in these simulations is:

$$
\pi_{i}\left(x_{i}, S\right)=a x_{i}-b x_{i}^{2}-c S-d S^{2}
$$


with $a, b, c, d>0$. The negative of the derivative with respect to emissions, $-\left(a-2 b x_{i}\right)$, represents the marginal abatement cost associated with emissions $x_{i}$. Country $i$ 's myopic BAU emission that maximizes the period-wise return is $x_{i}^{b}=x^{b} \equiv a /(2 b)$. As shown in the appendix, the value function is quadratic and a unique linear policy function exists for the efficient solution. The values $2 b$ and $2 d$ represent the slopes of the marginal costs of emission reduction and the marginal damages from pollution stock. Given that there is a wide range of uncertainty about the parameters, we consider a range of key parameter values used in the existing literature.

Next, we assume that the maximum feasible emissions is $\bar{x}_{i}=\bar{x}=a / b$ for all $i .{ }^{9}$. Thus, $\bar{S}=\frac{N a}{b(1-\lambda)}$. Finally, we assume that the initial stock is smaller than the potential steady state stock: $S_{0} \leq S^{*}$.

The strategy profile we investigate takes a particularly simple form: each country chooses $x_{i}^{*}(S)=x^{*}(S)$ for all $S \geq 0$ in phase $\mathrm{I}, 0 \leq x_{j}^{j}(S) \equiv z<x^{*}(S)$, for all $S \geq 0$ and all $j$, $x_{i}^{j}(S) \equiv y(S) \equiv \frac{X^{*}(S)-z}{N-1}$ for all $i \neq j$ in Phase $\mathrm{II} j$, and $T=1$.

Note that with this two-part punishment scheme, efficient aggregate emissions are chosen in phase II $j$.

\subsection{Parameter assumptions}

Following Nordhaus and Yang (1996) and Newell and Pizer (2003), we assume the decay rate of $\mathrm{CO}_{2}$ to be $0.83 \%$ and the retention rate of current emissions to be $64 \%$ (per year). The preindustrial stock level is $\underline{S}=613 \mathrm{GtC}$ (gigatons of carbon equivalent), while the initial stock level

\footnotetext{
${ }^{9}$ At this level, flow benefits vanish: $B\left(\bar{x}_{i}\right)=0$
} 
$S_{0}=787 \mathrm{GtC}$ (the level in 1995). Thus the carbon stock transition is given by

$$
S_{t+1}=613+0.9917\left(S_{t}-613\right)+0.64 X_{t} .
$$

We assume that country $i$ 's net benefit from emissions and the damage from stock are proportional to country $i$ 's national income:

$$
B\left(x_{i t}\right)=y_{t} \bar{B}_{i}\left(x_{i t}\right), \quad D\left(S_{t}\right)=y_{t} \bar{D}\left(S_{t}\right),
$$

where $\bar{B}$ and $\bar{D}$ represent the net benefit and damage as fractions of income, respectively. A key parameter in this inquiry is the ratio of the slope of marginal benefit to the slope of marginal abatement costs, $b / d$. We characterize this ratio at the global level, which we denote by $\gamma$. With $N$ identical countries, this parameter depends on $N, b$ and $d: \gamma=b /\left(d N^{2}\right) .{ }^{10}$ We consider a range of values for $\gamma$ including those used in the previous studies (e.g. Nordhaus and Boyer 2000, Newell and Pizer 2003, Karp and Zhang 2009).

Assuming income grows at the rate $1+g_{y}+n$, where $g_{y}$ is the per capita income growth rate and $n$ the population growth rate, and denoting initial income by $y_{0}$, the net benefits for country $i$ in year $t$ are

$$
\Pi_{i}\left(x_{i t}, S_{t}\right)=y_{0}\left(1+g_{y}+n\right)^{t} \bar{B}_{i}\left(x_{i t}\right)-y_{0}\left(1+g_{y}+n\right)^{t} \bar{D}_{i}\left(S_{t}\right) .
$$

With a discount factor $\bar{\delta}$, the present value of country $i$ 's payoff stream is

$$
\begin{array}{rlc}
\sum_{t=0}^{\infty} \bar{\delta}^{t} \Pi\left(x_{i t}, S_{t}\right) & = & \sum_{t=0}^{\infty} \bar{\delta}^{t}\left[y_{0}\left(1+g_{y}+n\right)^{t} \bar{B}\left(x_{i t}\right)-y_{0}\left(1+g_{y}+n\right)^{t} \bar{D}\left(S_{t}\right)\right] \\
& = & y_{0} \sum_{t=0}^{\infty}\left[\bar{\delta}\left(1+g_{y}+n\right)\right]\left[\bar{B}\left(x_{i t}\right)-\bar{D}\left(S_{t}\right)\right]
\end{array} .
$$

Then letting $r$ represent the consumption discount rate, the effective discount is given by

$$
\delta=\bar{\delta}\left(1+g_{y}+n\right)=\left(1+g_{y}+n\right) /(1+r) .
$$

\footnotetext{
${ }^{10}$ When $N$ identical countries choose the same emission level $x$, net global period-wise payoffs are $N\left(a x-b x^{2}-c S-d S^{2}\right)=a N x-(b / N)(N x)^{2}-N c S-N d S^{2}$. Thus, the ratio of slopes of global marginal abatement costs to global marginal damages is $\gamma=(b / N) /(N d)$.
} 
In the Ramsey formula under optimal growth, $r=\rho+\eta g_{y}$ where $\rho$ is the rate of time preference, $g_{y}$ is the growth rate of consumption, and $\eta$ is the elasticity of marginal utility. The effective discount factor in our model is therefore ${ }^{11}$

$$
\delta=\left(1+g_{y}+n\right) /\left(1+\rho+\eta g_{y}\right)
$$

To formalize the punishment regime, we set $z(S)=\alpha x *(S)$, where $0 \leq \alpha<1$ and $x *(S)$ is the efficient emission per country given stock $S$. The parameter $\alpha$ can be interpreted as a measure of the severity of punishment: if country $j$ cooperates in phase $\mathrm{II} j$, it would reduce the emissions by $100^{*}(1-\alpha)$ percent relative to the efficient level. As before, we assume that each country $i \neq j$ chooses $\left[X^{*}(S)-z(S)\right] /(N-1)$ in phase IIj. In phase IIj, countries $i \neq j$ collectively choose $X^{*}(S)$ $z(S)$, so total emissions across all countries is $X^{*}(S)$. We assume $T=1$.

\subsection{Findings}

Figure 1 illustrates a case where the efficient outcome can be sustained in a self-enforcing international agreement using the two-part punishment scheme (i.e., where $\phi^{*}$ is a subgame perfect equilibrium). Each curve in Figure 1 represents the net gains from playing according to $\phi^{*}$ versus the optimal deviation for country $j$ in Phase I, Phase II $j$, and Phase II $k$ at each stock level. That these curves are all positive over the complete range of potential stock sizes shows that there is no profitable deviation at any stage., for any feasible stock level. Further, having non-negative net gains from playing $\phi^{*}$ in Stage $\mathrm{II} j$, in which country $\mathrm{j}$ has to go along with the punishment of itself, is the most difficult condition to satisfy - consistent with Proposition 1,

[Figure 1]

\footnotetext{
${ }^{11}$ A number of recent studies discuss relevant values for these parameters when analyzing climate change (Stern et al. 2006, Nordhaus 2007, Dasgupta 2007). The values adopted in these studies imply a range of values for the discount rate.
} 
We now turn our attention to an analysis of the role played by the various parameters.

\subsubsection{Discount factor}

We begin by showing the influence of the discount factor on whether the efficient outcome can be sustained in a self-enforcing international agreement (Figure 2). ${ }^{12}$ We show the various combinations of the discount factors and the slope of the marginal damage function for which $\phi^{*}$ is a subgame perfect equilibrium (shaded areas in Figure 2). While the folk theorem tells us that any outcome with individual rational payoffs can be supported in a subgame perfect equilibrium in a repeated game so long as players are sufficiently patient, this result need not be true in dynamic games because the impact of the discount factor can be non-monotonic (Dutta, 1995b). In our model, we find cases where $\phi^{*}$ is a subgame perfect equilibrium at some discount factor and ceases to be subgame perfect as the discount factor is increased or decreased. As shown in Figure 2, for values of the slope of marginal damage function between 0.003 and 0.010 the profile $\phi^{*}$ is not subgame perfect when $\delta$ is too close to 1 or less than 0.96 but is subgame perfect for some intermediate values of the discount factor. In a repeated game, the only impact of a higher discount factor is to increase the weight on the future, which increases the weight of punishment relative to immediate gains from cheating. In a dynamic game like ours, however, changing the discount factor also changes the path of efficient emissions and the efficient steady state stock of GHGs in the atmosphere. As $\delta$ increases, the efficient level of emissions declines and the equilibrium stock of GHGs decreases. But this change makes cheating more valuable. Therefore, both the future payoff associated with $\phi^{*}$ and the payoff associated with optimal

\footnotetext{
${ }^{12}$ In order to highlight the role of the discount factor and the slopes of marginal abatement costs and marginal damages, Figures 1 and 2 apply hypothetical parameter values. Figures 3-7 assume the parameter values as discussed in section 3.1 .
} 
deviations increase. Movement along the arrow in Figure 2 indicates that the latter may increase by a larger amount than the former when the discount factor is sufficiently large. We note also that larger values of $d$ allow $\phi^{*}$ to be subgame perfect at smaller discount factors. We look further at the role played by marginal damages, in particular as they relate to marginal abatement costs, in the next subsection.

[Figure 2]

\subsubsection{Ratio of marginal abatement costs to marginal damages}

Here we consider the role of $\gamma$, the ratio of the slope of marginal abatement costs, $b$, to the slope of marginal damages, $d$, in determining whether $\phi^{*}$ is subgame perfect (Figure 3). As Figure 3 illustrates, $\phi^{*}$ is a subgame perfect equilibrium when this ratio is neither too large nor too small. At points like $\mathrm{H}$, where $b / d$ is large, the magnitude of marginal damages from the GHG stock is small relative to marginal abatement costs. At such parameter combinations, the difference between the level of efficient emissions and the level of non-cooperative emission is small, which makes the potential gains from a shift to an efficient outcome relatively small. For smaller values of $b / d$, marginal damages increase faster than the marginal abatement costs as pollution stock increases. Accordingly, the difference between the efficient emissions and noncooperative emission levels becomes larger. Because the efficient emission control calls for larger emission reduction for each country, both the gains from cooperation and temptations to deviate increase. When $b / d$ is not too small, the former exceeds the latter and $\phi^{*}$ is subgame perfect. However, at points like $\mathrm{L}$, the temptation to deviate exceeds the gains from cooperation and hence $\phi^{*}$ is not a subgame perfect equilibrium.

[Figure 3] 
Figure 4 illustrates whether $\phi^{*}$ is subgame perfect for a range of the values of $\gamma$ adopted from the literature for a range of discount factors $(0.97$ to 0.9999$)$. The red lines indicate three values of $\gamma$ used in the literature: $\gamma=12,269$ (Karp and Zhang 2009), $\gamma=53,630$ (Nordhaus and Boyer 2000), and $\gamma=183,908$ (Newell and Pizer 2003). ${ }^{13}$ This figure has several important implications. First, for smaller values of $\gamma$, there is small range of discount factors for which $\phi^{*}$ is subgame perfect. Therefore, more optimistic estimates of the slope of the marginal abatement costs or more pessimistic estimates about the slope of the marginal damages, both of which would reduce $\gamma$, could reduce the likelihood of a successful agreement. Second, for sufficiently small values of $\gamma$, the effect of the discount rate on whether $\phi^{*}$ is subgame perfect is nonmonotonic, as discussed above.

\section{[Figure 4]}

Figure 5 describes the range of $\gamma$ and $\alpha$ that make $\phi^{*}$ subgame perfect. The variable $\alpha$ is measure of the severity of punishment with lower values of $\alpha$ indicating more severe punishment. More severe punishment makes it less likely that a country would find it profitable to cheat in Phase I, but more likely that country $j$ would find it profitable to cheat and not follow through on punishment of itself in Phase IIj. For the treaty to be self-enforcing the sanction should be neither too stringent nor too lenient. For high values of $\gamma$, the sanction should be relatively lenient as it is difficult to satisfy the constraint on not cheating in Phase II $j$. For lower values of $\gamma$, punishment must become more severe. For really low values of $\gamma$ there is no value of $\alpha$ that makes $\phi^{*}$ subgame perfect.

\footnotetext{
${ }^{13}$ Other studies have used estimates of $\gamma$ of the same order of magnitude (e.g. Hoel and Karp 2002, Falk and Mendelsohn 1993, Reilly 1992). See the appendix for a brief survey of the estimates of $\gamma$ used in the literature.
} 
[Figure 5]

\subsubsection{Number of Countries}

An important practical consideration for treaty negotiation is whether an agreement can work when there are a large number of countries involved. Figure 6 describes the impact of the number of countries on whether $\phi^{*}$ is subgame perfect. The most striking feature of the analysis is that for these particular set of parameter values there is a hard cap at $N=8$. For $N>8$, there is no possibility of a self-enforcing efficient outcome. For $\mathrm{N}<8$, whether $\phi^{*}$ is subgame perfect also depends on $\gamma$. For small values, an increase in $\gamma$ can facilitate a larger coalition. However, past a certain point - in our simulations, between the values of $\gamma$ associated with the Karp and Zhang and the Nordhaus and Boyer studies - further increases in $\gamma$ do not engender larger coalitions. While there are over 190 countries involved in the climate negotiations, the lion's share of emissions can be attributed to a small number of countries. China, the European Union, India, Japan, Russia and the United States $(N=6)$ are collectively responsible for nearly $70 \%$ of global CO2 emissions (WRI 2015).

[Figure 6]

\subsubsection{Elasticity of marginal utility, income growth rate, and rate of time preference}

Since the Stern Review of the Economics of Climate Change was published, economists have debated the proper discount rate and the other parameter values in the Ramsey formula (e.g. Nordhaus 2007a, b, Weitzman 2007, Dasgupta 2007, Heal 2009). The following exercise illustrates the implication of the choice of these parameter values on whether $\phi^{*}$ is subgame perfect.

Recall the formula for the effective discount factor in this model:

$$
\delta \equiv\left(1+g_{y}+n\right) /\left(1+\rho+\eta g_{y}\right) .
$$


Figure 7 describes the impact of changes in $\rho$, the rate of time preference, $\eta$, the elasticity of marginal utility, and $g_{y}$, the per capita income growth rate. Results are presented for each of the three values of $\gamma$ employed in Figures 4 and $5 .{ }^{14}$ For a low value of $\gamma$ (panel a), we find a nonmonotonic relationship with the pure rate of time preference, consistent with results shown above on the non-monotonic relation of the discount factor. Paradoxically, for a low value of $\gamma$, having a low value of $\rho$ and $\eta$ as in the Stern Review means that a self-enforcing international agreement is not possible. This paradoxical result does not hold for higher values of $\gamma$ (panels B and C). In all cases, however, the set of parameter combinations $\left(\rho, g_{y}\right)$ for which $\phi^{*}$ is subgame perfect shrinks as $\eta$ increases. In addition, we observe a trade-off between $\rho$ and $g_{y}$ when $\eta$ is sufficiently large.

[Figure 7]

\section{An Example with Heterogeneous Countries}

In reality, there are important differences between countries in terms of both the damages from climate damages and the costs of mitigation. In this section, we discuss an extension of the model to allow for heterogeneous payoffs. To this end, we assume the punishment phase is characterized by $x_{j}^{j}(S) \equiv 0$ for all $S \geq 0$ and all $j$ and $x_{i}^{j}(S) \equiv x_{i}^{b}$ (the myopic BAU emission) for all $i \neq j$. We retain the earlier assumption that $S_{0} \leq S^{*}$.

We allow transfers among countries. Let $\tau_{i t}$ be the net transfer to country $i$ in period $t$ where $\sum_{i} \tau_{i t}=0$ for all $t$. Country $i$ 's net one-period return in period $t$ is given by $\pi_{i}\left(x_{i t}, S_{t}\right)+\tau_{i t}$. In the context of climate-change mitigation, the transfers would be determined

\footnotetext{
${ }^{14}$ We assume that $n=0.82 \%$. The world population in 2000 was 6,124 million, while the median forecast of the population in 2050 was 9,191 million (United Nations, 2007). Hence, the average annual population growth rate between 2000 and 2050 is about $0.82 \%$.
} 
based on cost burden sharing agreed on by the countries.

Suppose the value to country $i$ is given by $\sigma_{i} V$ where $\sigma_{i} \geq 0$ and $\sum_{i} \sigma_{i}=1$. Define a transfer $\tau^{*}$ where

$$
\tau_{i}^{*}(S) \equiv \sigma_{i} \sum_{j} \pi_{j}\left(x_{j}^{*}(S), S\right)-\pi_{i}\left(x_{i}^{*}(S), S\right)
$$

for all $S$ and all $i$. By choosing $x^{*}$ and $\tau^{*}$, the countries realize the efficient outcome with the shares induced by $\sigma$.

Figure 8 describes the gains from cooperation under the treaty for a game with four heterogeneous countries. We characterize these countries by combinations of BAU emissions and values of the ratio $b / d$. Countries 1 and 3 have low BAU emissions $\left(a_{i} /(2 b)\right)$, while countries 2 and 4 have high BAU emissions; countries 1 and 2 have a low value of $b / d$ while countries 3 and 4 have a high value of $b / d$. In particular, $a_{i}=10.2(10.0)$ for countries with high (low) BAU emissions, while $b_{i} / d_{i}=62,500(50,000)$ for countries with a high (low) $b / d$ ratio. We assume $\lambda=.99$ and $\mathrm{c}=0$ for all four countries. We also assume $v_{i}=V / N$ for all $i$, i.e. the payoffs upon cooperation are divided equally across countries. We discuss results for two levels of the discount rate: $\delta=1 / 1.1$ (the left-most panel) and $\delta=1 / 1.025$ (the right-most panel).

With this example, conditions (1) and (3) under which $\phi^{*}$ is a subgame perfect equilibrium holds given the discount factor values considered $(2.5 \%, 10 \%)$. The steady state is about 320 when $\delta=1 / 1.1$ and 222 when $\delta=1.1 .025$. Two broad patterns emerge from these simulations. First, for both countries 1 and 2 (each of which has a low value for $b / d$ ), the gains from cooperation are increasing in the stock of GHGs. For countries 3 and 4 (the countries with high values of $b / d$ ), the gains from cooperation are increasing in the stock of GHGs when the discount factor is sufficiently low, but decreasing in the stock of GHGs when the discount factor 
is sufficiently large. For all four countries, the gains from cooperation are positive for all values of the GHG stock when the discount rate is $2.5 \%$; accordingly, a self-enforcing agreement exists in this case. On the other hand, countries 3 and 4 do not gain from cooperation when the discount rate is $10 \%$; accordingly, a self-enforcing agreement does not exist in this case. We also note that for a given value of $b / d$, the gains from cooperation are larger for countries with lower BAU emissions. This is intuitive. Given equal sharing of $V$, a country with higher BAU emissions has less to lose by deviation than a country with lower BAU emissions. Similarly, a country with lower marginal damages has less to lose from deviation than does a country with higher marginal damages. Despite these differences, this example illustrates the potential for the strategy we propose a self-enforcing agreement to exist even with heterogeneity among countries.

[Figure 8]

\section{Discussion}

Climate change mitigation is a global public good but reducing GHG emissions is costly for any country undertaking mitigation. In order for sovereign countries to abide by an international agreement to control GHG emissions, the agreement must be self-enforcing for each country, which is a difficult proposition given the structure of the climate change problem. We applied dynamic game theory to illustrate how an international agreement with a simple approach to sanctions can support the efficient level of climate-change mitigation in a self-enforcing manner. We considered a two-part punishment scheme where all countries penalize a country for not upholding its obligations under the agreement, followed by a resumption of the international agreement. The two-part punishment scheme is designed so that all countries do not have any incentive to cheat on the agreement in the first place and have an incentive to carry out the punishment should that be required. 
Using a simple climate-change model, we examined conditions under which an efficient level of GHG mitigation can be achieved as a subgame perfect equilibrium under the two-part punishment scheme. We find there are a range of plausible parameter values where the efficient outcome is achieved as a subgame perfect equilibrium. While one might expect that it should be easier for countries to avoid free riding and abide by the international agreement as discount factor or the stock of GHG in the atmosphere increases, our simulation results indicate that this is not necessarily the case. Whether the international agreement treaty is self-enforcing depends nonlinearly on the countries' discount factor and GHG stock. While the international agreement is not self-enforcing for sufficiently small discount factors, we also find cases where an increase in the discount factor makes the agreement no longer self-enforcing. We also find nonmonotonicity regarding the marginal benefits and costs of GHG emission reduction: a selfenforcing agreement does not exist when the slope of the marginal benefits of GHG emission is too large or too small relative to the slope of the marginal abatement cost. Our linear-quadratic example illustrates that these non-linear relationships are relevant over the range of values of key parameters - discount factor, elasticity of marginal utility, marginal benefits and costs of GHG emission reduction — that are used in previous numerical studies on climate change.

We also investigated a variant of our model that allows for differences in BAU emissions and damages. We find that countries with larger BAU emissions or lower marginal damages are less inclined to participate in the international agreement.

The approach to designing an international agreement at the Paris Climate Change Conference in December 2015 was quite different than the approach of designing a selfenforcing agreements analyzed in this paper. For Paris, individual countries made pledges to reduce their emissions of GHGs but without an explicit enforcement mechanism to penalize a 
country that fails to follow through on its pledge. Therefore, meaningful pledges cannot go beyond what is in a country's self-interest to do unilaterally. But what is in a country's selfinterest will typically be quite different from what is optimal from a global perspective. Indeed, analysts have pointed out that while pledges made in Paris are a step in the right direction, they fall well short of what is needed to avoid dangerous climate change (see for example the analysis done by Climate Interactive; www.climateinteractive.org).

The dynamic-game formulation provides a useful framework for analyzing a selfenforcing treaty for climate-change mitigation, an approach that may be necessary to reach an efficient solution. The dynamic-game formulation allows for analysis of two-part punishment under changing levels of atmospheric GHGs and provides insights not available from static-game or even repeated-game analysis.

The game-theoretic approach taken in this paper-with key assumptions including nonlinear damages and emission abatement costs, limited-term sanctions, and feedback strategies used by countries - can be used for further analysis of self-enforcing treaties. Heterogeneity among countries and its implications toward treaty design should be further explored. Countries differ in costs and benefits regarding climate-change mitigation as well as the GHG emission levels in the past and in the future. How such countries should share the cost of GHG emission reduction is a crucial issue (Germain et al. 2003, Chakravarty et al. 2009). Future research should investigate the role of transfers and the self-enforcing transfer mechanisms. ${ }^{15}$ Future research should also address a number of assumptions that we made to keep our analysis simple. We assumed no technological progress and the same income and population growth rates for all countries in the analytical model. Other natural extensions of our model would be to incorporate uncertainty regarding climate change, and to consider sanctions through means other than

\footnotetext{
${ }^{15}$ Yang and Nordhaus (2006) address the issue of technology transfers in the context of climate change mitigation.
} 
increased emissions such as trade (Barrett 2003, Lockwood and Whalley 2010). A temporary trade sanctions may be less costly for each country than sanctions with increased emissions, the effect of which will last for a long time because of the nature of GHG as a stock pollutant, and therefore increase the likelihood of a self-enforcing treaty.

\section{References}

Aldy, J., Barrett, S., Stavins, R. N. (2003) Thirteen Plus One: a Comparison of Global Climate Policy Architectures, RFF Working Paper.

Aldy, J., A.J. Krupnick, R.G. Newell, I.W.H. Parry, and W.A. Pizer. (2010). Designing Climate Change Policy. Journal of Economic Literature 47(4), 903-936.

Abreu, D. (1988) On the Theory of Infinitely Repeated Games with Discounting. Econometrica, 56, 383-396.

Barrett, S. (1994) Self-enforcing International Environmental Agreements. Oxford Economic Papers, 46, 878-94.

Barrett, S. (2003) Environment and Statecraft. Oxford University Press, Oxford, UK.

Barrett, S. (2008) Climate Treaties and the Imperative of Enforcement. Oxford Review of Economic Policy, 24, 239-258.

Battaglini, M. and B. Harstad. (2015) Participation and duration of environmental agreements. Journal of Political Economy, in press.

Benhabib, J. and R. Radner. (1992) The Joint Exploitation of a Productive Asset: A GameTheoretic Approach. Economic Theory, 2, 155-190.

Bosello, F., B. Buchner and C. Carraro. (2003) Equity, Development, and Climate Change Control. Journal of the European Economic Association, 1, 601-611. 
Broecker, W.S. (1997) Thermohaline Circulation, the Achilles Heel of our Climate System: Will Manmade CO2 Upset the Current Balance? Science, 278, 1582-1588.

Carraro, C. and D. Siniscalco. (1993) Strategies for the International Protection of the Environment. Journal of Public Economics, 52, 309-328.

Chakravarty, S., A. Chikkatur, H. d. Coninck, S. Pacala, R. Socolow, M. Tavoni. (2009) Sharing Global CO2 Emission Reductions among One Billion High Emitters. Proceedings of the National Academy of Sciences, 106(29), 11884-11888.

Chander, P. and H. Tulkens. (1995) A Core-theoretic Solution for the Design of Cooperative Agreements on Transfrontier Pollution. International Tax and Public Finance, 2(2), 279293.

Cline, W. (1992) The Economics of Global Warming. Institute of International Economics, Washington, D.C.

Dasgupta, P. (2006) Comments on the Stern Review's Economics of Climate Change. Working Paper, Cambridge University.

d'Aspremont, C. A., J. Jacquemin, J. Gabszeweiz and J. A. Weymark. (1983) On the Stability of Collusive Price Leadership. Canadian Journal of Economics, 16, 17-25.

Dayton-Johnson, J., and P. Bardhan. (2002) Inequality and Conservation on the Local Commons: A Theoretical Exercise. Economic Journal, 112, 577-602.

de Zeeuw, A. (2008) Dynamic Effects on the Stability of International Environmental Agreements. Journal of Environmental Economics and Management, 55, 163-174.

Dockner, E. J., N. V. Long and G. Sorger. (1996) Analysis of Nash Equilibria in a Class of Capital Accumulation Games. Journal of Economic Dynamics and Control, 20, 12091235. 
Dutta, P.K. and R.K. Sundaram. (1993) The Tragedy of the Commons? Economic Theory, 3, 413-426.

Dutta, P.K. (1995a) A Folk Theorem for Stochastic Games. Journal of Economic Theory, 66, 132.

Dutta, P.K. (1995b) Collusion, Discounting and Dynamic Games. Journal of Economic Theory, 66, 289-306.

Dutta, P.K. and R. Radner. (2004) Self-enforcing Climate-change Treaties. Proceedings of the National Academy of Sciences, 101, 5174-5179.

Dutta, P.K. and R. Radner. (2006a) A Game-Theoretic Approach To Global Warming, in Advances in Mathematical Economics, Vol. 8, pp. 135 - 153.

Dutta, P.K. And R. Radner. (2006b) Population Growth and Technological Change in a Global Warming Model. Economic Theory, 29, 251-270.

Dutta, P. K. and R. Radner. (2009) Strategic Analysis of Global Warming: Theory and Some Numbers. Journal of Economic Behavior and Organization, 71(2), 187-209.

Ellerman, A. D. and A. Decaux. (1998) “Analysis of Post-Kyoto CO2 Emissions Trading Using Marginal Abatement Curves," Joint Program on the Science and Policy of Global Change, MIT Press, Cambridge.

Eyckmans, J. and H. Tulkens. (2003) Simulating Coalitionally Stable Burden Sharing Agreements for the Climate Change Problem. Resource and Energy Economics, 25, 299327.

Falk, I. and R. Mendelsohn. (1993) The Economics of Controlling Stock Pollutants: An Efficient Strategy for Greenhouse Gases. Journal of Environmental and Economic Management, 25, 76-88. 
Fankhauser, S. (1995) Valuing Climate Change - The Economics of the Greenhouse. EarthScan, London.

Finus, M. (2001) Game Theory and International Environmental Cooperation. Edward Elgar, London.

Fudenberg, D. and E. Maskin. (1986) The Folk Theorem in Repeated Games with Discounting or with Incomplete Information. Econometrica, 54, 533-554.

Fudenberg, D. and J. Tirole. (1991) Game Theory. MIT Press, Cambridge, MA.

Garnaut, R. (2008) Garnaut Climate Change Review. Cambridge University Press, Cambridge.

Germain, M., P. Toint, H. Tulkens, and A. de Zeeuw. (2003) Transfers to Sustain Dynamic Coretheoretic Cooperation in International Stock Pollutant Control. Journal of Economic Dynamics and Control, 28(1), 79-99.

Golosov, M., J. Hassler, P. Krusell, and A. Tsyvinski. (2014) Optimal taxes on fossil fuels in general equilibrium. Econometrica, 82(1), 41-88.

Gordon, H.S. (1954) The Economic Theory of a Common Property Resource: The Fishery. Journal of Political Economy, 62, 124-142.

Green, E.J. and R.H. Porter. (1984) Noncooperative Collusion under Imperfect Price Information. Econometrica, 52, 87-100.

Harstad, B. (2012) Climate contracts: A game of emissions, investments, negotiations, and renegotiations. Review of Economic Studies, 79, 1527-1557.

Harstad, B. (2014) The dynamics of climate agreements. Working paper.

Heal, G. (2009) Climate Economics: A Meta-Review and Some Suggestions for Future Research. Review of Environmental Economics and Policy, 3, 4-21.

Hoel, M. and L. Karp. (2001) Taxes and Quotas for a Stock Pollutant with Multiplicative 
Uncertainty. Journal of Public Economics, 82, 91-114.

Hoel, M., L. Karp. (2002) Taxes Versus Quotas for a Stock Pollutant. Resource and Energy Economics, 24, 367-384.

Hope, C.W. (2006) The Marginal Impact of CO2 from PAGE2002: An Integrated Assessment Model Incorporating the IPCC's Five Reasons for Concern. Integrated Assessment Journal, 6(1), $19-56$.

Hope, C.W. (2008) Optimal Carbon Emissions and the Social Cost of Carbon over Time under Uncertainty.” Integrated Assessment Journal, 8(1), 107-122.

Hufbauer, J. C., J. J. Schott, and K. A. Elliott. (1985) Economic Sanctions Reconsidered. Institute for International Economics, Washington, D.C.

Intergovernmental Panel on Climate Change (IPCC). (2014) Climate Change 2014: Synthesis Report. Contribution of Working Groups I, II and III to the Fifth Assessment Report of the Intergovernmental Panel on Climate Change. Core Writing Team, R.K. Pachauri and L.A. Meyer (eds.). IPCC, Geneva, Switzerland.

Kattenberg, A., Giorgi, F., Grassl, H., Meehl, G. A., Mitchell, J., Stouffer, R. J., Tokioka, T., Weaver, A. J., and Wigley, T. M. (1996) Climate Models—Projections of Future Climate. In Climate Change 1995: The Science of Climate Change (eds. Houghton, J. T., Meiro Filho, L. G., Callendar, B. A., Harris, N. Kattenberg, A., and Maskell, K.). p 285-358. Cambridge University Press, Cambridge, UK.

Karp, L. and J. Zhang. (2005) Regulation of Stock Externalities with Correlated Abatement Costs. Environmental and Resource Economics, 32, 273-300.

Karp, L. and J. Zhang. (2006) Regulation with Anticipated Learning about Environmental Damages. Journal of Environmental Economics and Management, 51, 259-279. 
Karp, L. and J. Zhang. (2009) Taxes Versus Quantities for a Stock Pollutant with Endogenous Abatement Costs and Asymmetric Information. Economic Theory, forthcoming.

List, J. A. and C. F. Mason. (2001) Optimal Institutional Arrangements for Transboundary Pollutants in a Second-Best World: Evidence from a Differential Game with Asymmetric Players. Journal of Environmental Economics and Management, 42, 277-296.

Lockwood. B. and J. Whalley. (2010) Carbon Motivated Border Tax Adjustments: Old Wine in Green Bottles? World Economy, 33, 810-819.

Maddison, D.J. (1995) A Cost-Benefit Analysis of Slowing Climate Change. Energy Policy, 23, $337-346$.

Manne, A. and R. Richels. (1992) Buying Greenhouse Insurance: The Economic Costs of CO2 Emission Limits. MIT Press, Cambridge, MA.

Mäler, K-G. and A. de Zeeuw. (1998) An Acid Rain Differential Game. Environmental and Resource Economics, 12, 167-184.

Martin, W.E., R.H. Patrick and B. Tolwinski. (1993) A Dynamic Game of a Transboundary Pollutant with Asymmetric Players. Journal of Environmental Economics and Management, 25(1), 1-12.

Mason, C. F. and S. Polasky. (1994) Entry Deterrence in the Commons. International Economic Review, 35, 507-525.

Mason, C. F. and S. Polasky. (2002) Strategic Preemption in a Common Property Resource: A Continuous Time Approach. Environment and Resource Economics, 23, 255-278.

Mason, C. F. and S. Polasky. (2005) What Motivates Membership in Non-renewable Resource Cartels?: The Case of OPEC. Resource and Energy Economics, 27, 321-342.

Mendelsohn, R.O. (2006) A Critique of the Stern Report. Regulation (Winter 2006/2007), 42-46. 
Mendelsohn, R.O., W. Morrison, M.E. Schlesinger, and N.G. Andronova. (2000) Country Specific Market Impacts of Climate Change. Climatic Change, 45, 553-569.

Newell, R. G. and W. A. Pizer. (2003) Regulating Stock Externalities under Uncertainty. Journal of Environmental Economics and Management, 45, 416-432.

Nordhaus, W.D. (1991) To Slow or Not to Slow: The Economics of the Greenhouse Effect. Economic Journal, 101, 920-937.

Nordhaus, W. D. (1994) Managing the Global Commons. MIT Press, Cambridge, MA.

Nordhaus, W. D. (1998) Revised Estimates of the Impacts of Climate Change. Working Paper, Yale University.

Nordhaus, W.D. (2007a) Critical Assumptions in the Stern Review on Climate Change. Science, 317, 201-202.

Nordhaus, W.D. (2007b) The Stern Review of the Economics of Climate Change. Journal of Economic Literature, 45(3), 686-702.

Nordhaus, W.D. (2008) A Question of Balance: Economic Models of Climate Change. Yale University Press, New Haven, CT.

Nordhaus, W.D. (2010) Economic Aspects of Global Warming in a Post-Copenhagen Environment. Proceedings of the National Academy of Sciences, 107(26), 11721-11726.

Nordhaus, W. D., Z. Yang. (1996) A Regional Dynamic General-Equilibrium Model of Alternative Climate-Change Strategies. American Economic Review, 96, 741-765.

Nordhaus, W. D., J. Boyer. (2000) Warming the World: Economic Models of Global Warming. MIT Press, Cambridge, MA.

Olson, M. (1965) The Logic of Collective Action. Harvard University Press, Cambridge.

Ostrom, E. (1990) Governing the Commons: The Evolution of Institutions for Collective Action. 
Cambridge University Press.

Ostrom, E. Collective Action and the Evolution of Social Norms. (2000) Journal of Economic Perspectives, 14, 137-158.

Polasky, S., N. Tarui, G. Ellis, and C. Mason. (2006) Cooperation in the Commons. Economic Theory, 29, 71-88.

Reilly, J.M. (1992). Climate-change Damage and the Trace-Gas-Index Issue. In: Reilly, J.M., Anderson, M. (Eds.), Economic Issues in Global Climate Change: Agriculture, Forestry, and Natural Resources. Westview Press.

Rubio, S.J. and A. Ulph (2007) An Infinite-horizon Model of Dynamic Membership of International Environmental Agreements. Journal of Environmental Economics and Management, 54, 296-310.

Rustichini, A. (1992) Second Best Equilibria for Games of Joint Exploitation of a Productive Asset. Economic Theory, 2, 191-196.

Schlenker, W., M. J. Roberts. (2006) Nonlinear Effects of Weather on Corn Yields. Review of Agricultural Economics, 28(3), 391-398.

Schlenker, W., W. M. Hanemann, A. C. Fisher. (2006) The Impact of Global Warming on U.S. Agriculture: An Econometric Analysis of Optimal Growing Conditions. Review of Economics and Statistics, 88(1), 113-125.

Stern, N. (2008) The Economics of Climate Change. American Economic Review 98: 1 -37.

Stern, N.H., S. Peters, V. Bakhshi, A. Bowen, C. Cameron, S. Catovsky, D. Crane, S. Cruickshank, S. Dietz, N. Edmonson, S.-L. Garbett, L. Hamid, G. Hoffman, D. Ingram, B. Jones, N. Patmore, H. Radcliffe, R. Sathiyarajah, M. Stock, C. Taylor, T. Vernon, H. Wanjie, and D. Zenghelis. (2006) Stern Review: The Economics of Climate Change. 
Cambridge University Press, Cambridge.

Stern, N.H. and C. Taylor. (2007) Climate Change: Risks, Ethics and the Stern Review. Science, 317, 203-204.

Tarui, N., C. F. Mason, S. Polasky, and G. Ellis. (2008) Cooperation in the Commons with Unobservable Actions. Journal of Environmental Economics and Management, 55, 3751.

Tol, R.S.J. (1995) The Damage Costs of Climate Change Toward More Comprehensive Calculations. Environmental and Resource Economics, 5, 353-374.

Tol, R.S.J. (2005) The Marginal Damage Costs of Carbon Dioxide Emissions: An Assessment of the Uncertainties. Energy Policy, 33, 2064-2074.

Tol, R.S.J. (2007) The Social Cost of Carbon: Trends, Outliers and Catastrophes. Economics Discussion Papers. Discussion Paper 2007-44.

Tol, R.S.J. and G.W. Yohe. (2006) A Review of the Stern Review. World Economics, 7, 233-250. United Nations (2007) World Population Prospects: The 2006 Revision. United Nations.

Weitzman, M.L. (2007) A Review of the Stern Review on the Economics of Climate Change. Journal of Economic Literature, 45, 703-724.

World Resources Institute. 2015. CAIT Climate Data Explorer. World Resources Institute: Washington, DC. http://cait.wri.org

Yang, Z. (2003) Reevaluation and Renegotiation of Climate Change Coalitions-A Sequential Closed-loop Game Approach. Journal of Economic Dynamics and Control, 27, 15631594.

Yang, Z. and W. D. Nordhaus. (2006) Magnitude and Direction of Technological Transfers for Mitigating GHG Emissions. Energy Economics, 28, 730-741. 
Yohe, G.W., R.S.J. Tol, and D. Murphy. (2007) On Setting Near-Term Climate Policy while the Dust Begins to Settle -- The Legacy of the Stern Review. Energy \& Environment, 18, 621-633. 


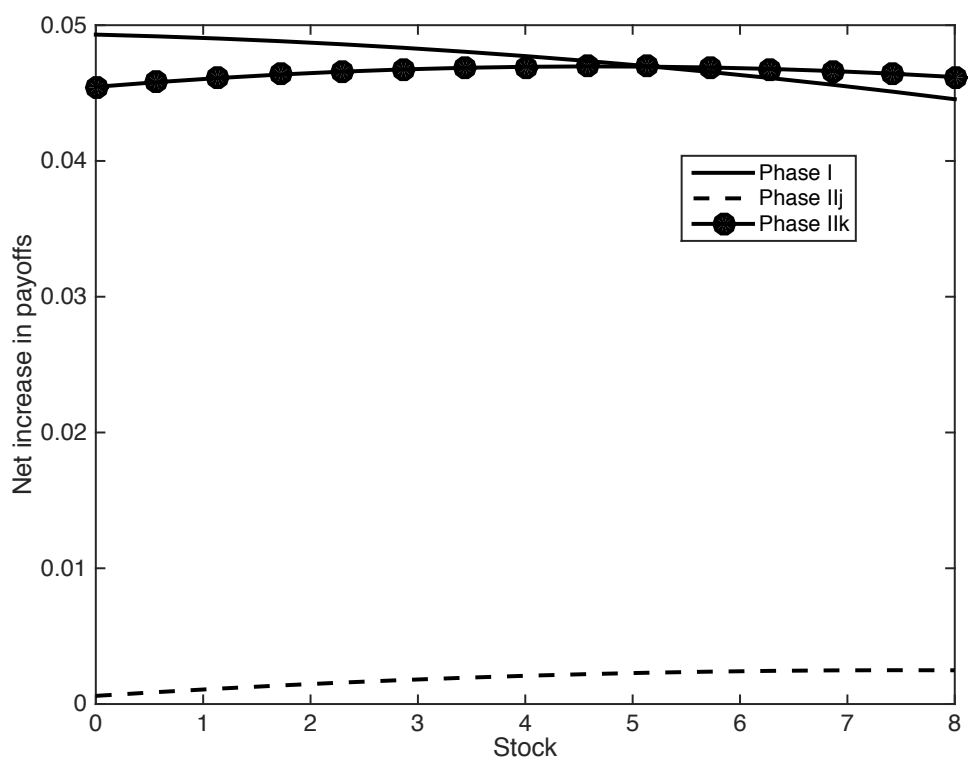

Figure 1: An example where $\phi^{*}$ is a subgame perfect equilibrium. Parameter values: $a=10, b=500, c=0, d=$ $0.001, N=4, \delta=\lambda=0.99, \underline{S}=\beta=0$, and $z=0$. With these parameter values, the efficient steady state GHG stock is 3.45 while the maximum feasible stock $\bar{S}$ is 8 .

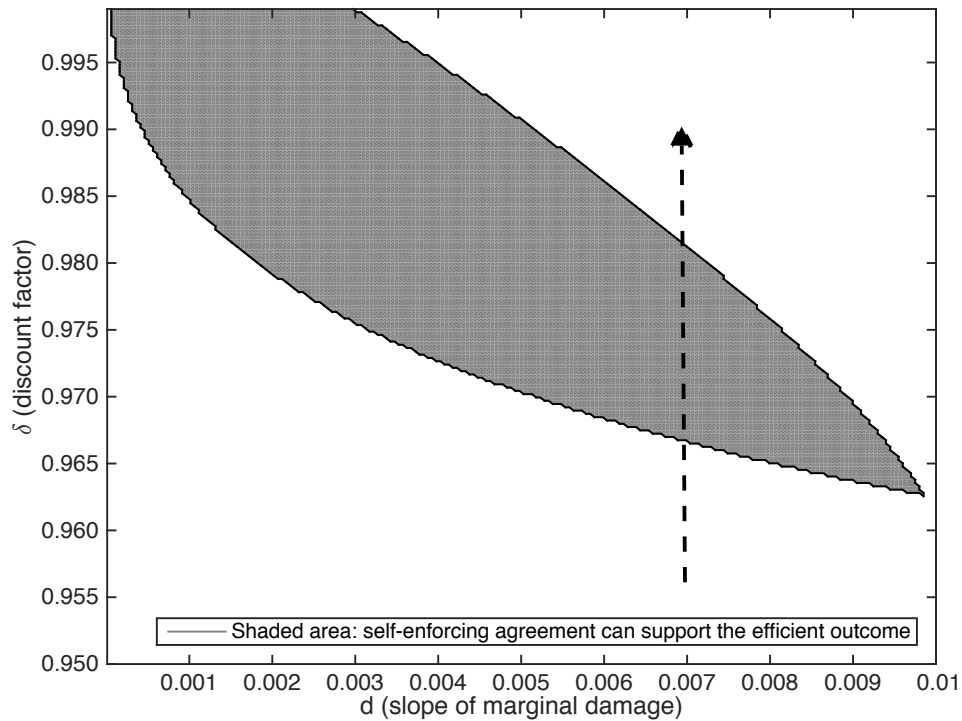

Figure 2: Impact of the discount factor on whether an efficient self-enforcing agreement exists. Parameter values: $a$ $=10, b=500, c=0, N=4, \underline{S}=\beta=0, \lambda=0.99$, and $z=0$. 


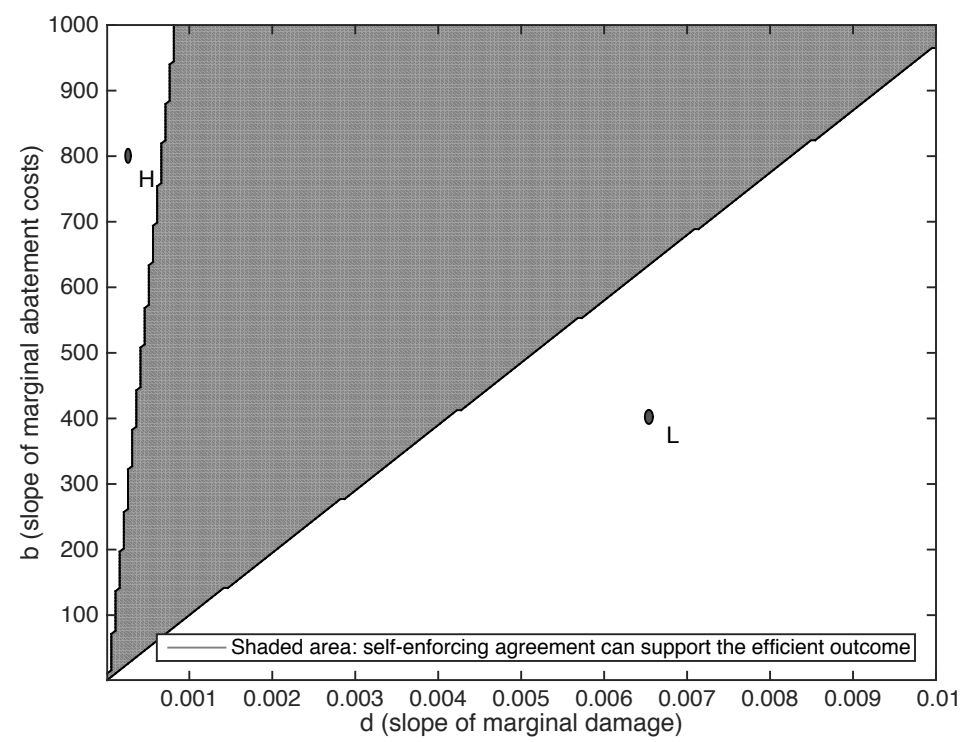

Figure 3: Impact of the slope of marginal damages and the slope of marginal costs on whether a an efficient selfenforcing agreement exists. Parameter values: $a=10, c=0, N=4, \delta=\lambda=0.99, \underline{S}=\beta=0$, and $z=0$.

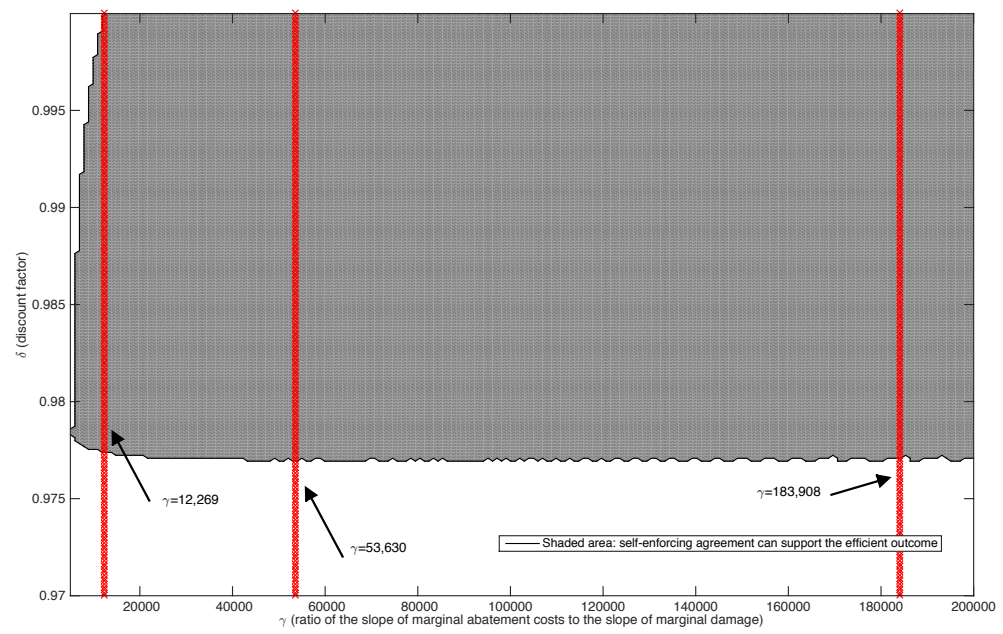

Figure 4: Illustration of whether an efficient self-enforcing agreement exists for a range of realistic parameter values from the literature for the ratio of the slopes of marginal abatement cost and marginal damages, and different discount factors. Parameter values: $N=6, c=-0.1421, d=1.0032 * 10^{-4}, b=$ $N d \gamma, a=2(b / N) \bar{E}$ where $\bar{E}=6.1586$ is the global $\mathrm{CO} 2$ emissions missions from fossil-fuel burning (in million tC) as of $1995, \underline{S}=613, \beta=0.64$. Parameter $\alpha$ is allowed to vary between 0 and 1 . 


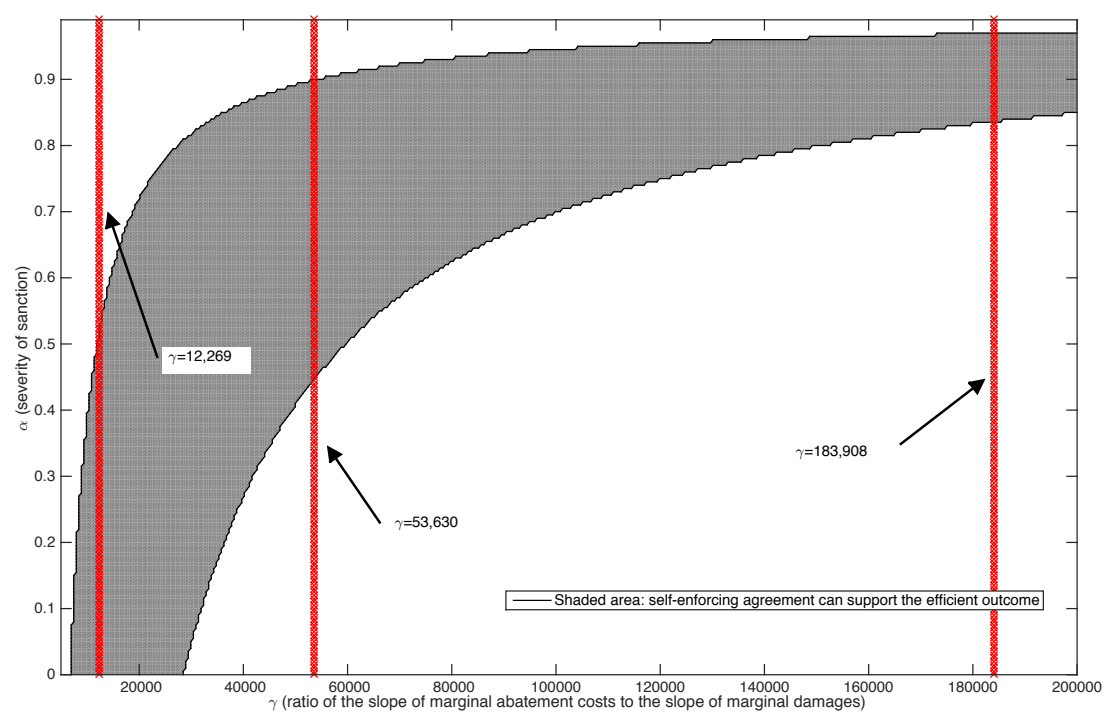

Figure 5: Illustration of whether an efficient self-enforcing agreement exists for a range of realistic parameter values from the literature for the ratio of the slopes of marginal abatement cost and marginal damages, and different levels of sanctions. The severity of sanctions that enforce an agreement varies with gamma. Parameter values: $N=6, c=-0.1421, d=1.0032 * 10^{-4}, b=N d \gamma, a=2(b / N) \bar{E}$ where $\bar{E}=6.1586$ is the global CO2 emissions missions from fossil-fuel burning (in million tC) as of 1995 , $\underline{S}=613, \beta=0.64$, and $\delta=1 / 1.01$.

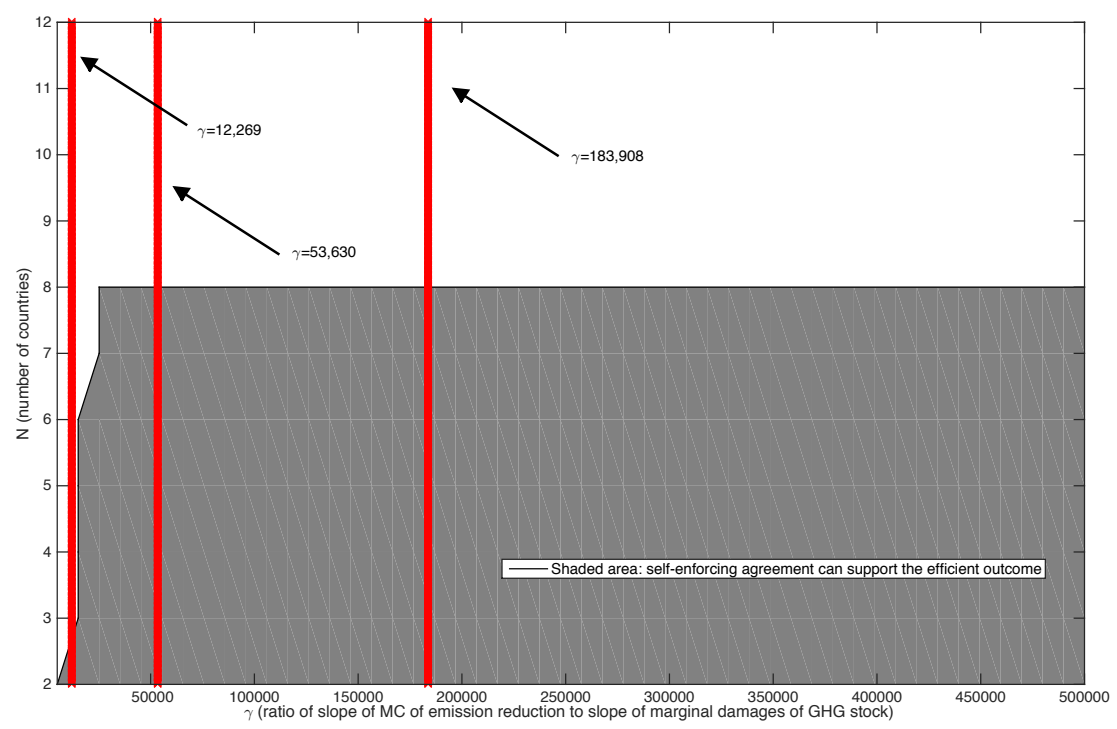

Figure 6: Impact of the number of countries on whether an efficient self-enforcing agreement exists. Parameter values: $c=-0.1421, d=1.0032 * 10^{-4}, b=N d \gamma, a=2(b / N) \bar{E}$ where $\bar{E}=6.1586$ is the global CO2 emissions missions from fossil-fuel burning (in million tC) as of 1995, $\underline{S}=613, \beta=0.64$, and $\delta=1 / 1.01$. Parameter $\alpha$ is allowed to vary between 0 and 1 . 
(a) $\gamma=12,269$
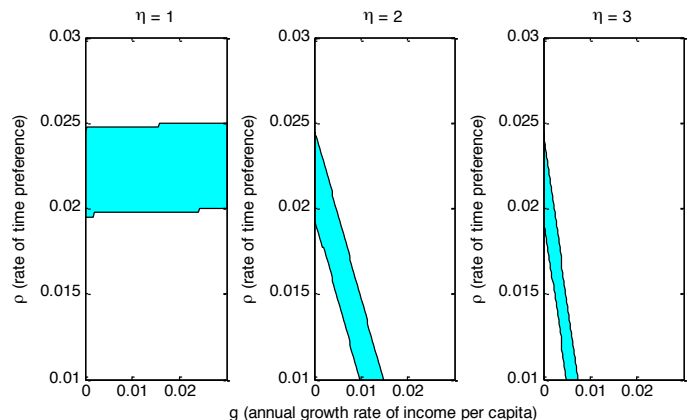

(b) $\gamma=53,630$
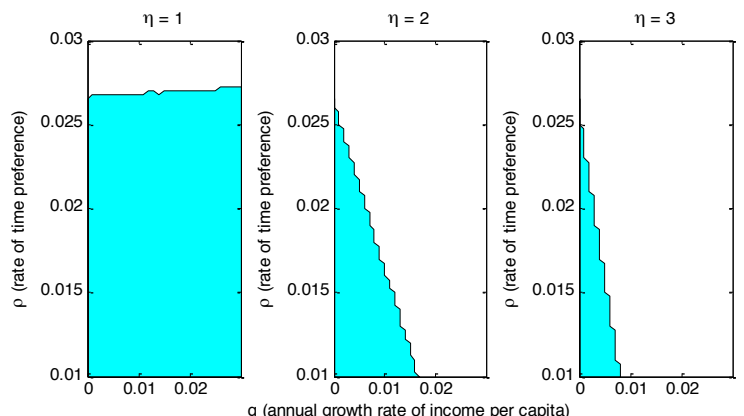

(c) $\gamma=183,908$

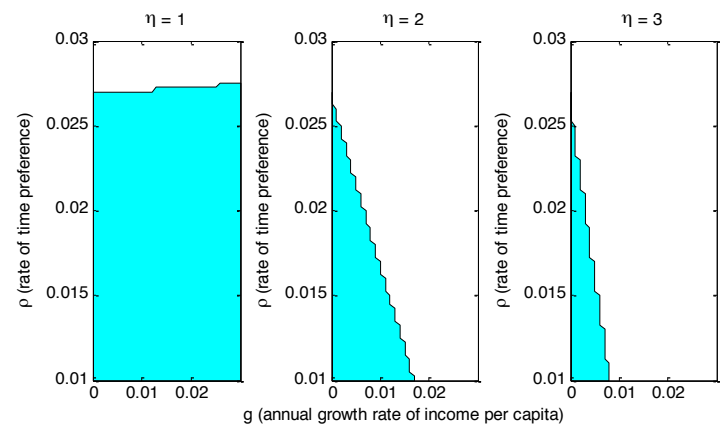

Figure 7: The effect of time preference and income growth rate on whether an efficient self-enforcing agreement exists for different values of the elasticity of marginal utility and for different levels of the ratio of the slopes of marginal abatement cost and marginal damages,. Parameter values: $N=6, c=-0.1421, d=1.0032 * 10^{-4}, b=$ $N d \gamma, a=2(b / N) \bar{E}$ where $\bar{E}=6.1586$ is the global CO2 emissions missions from fossil-fuel burning (in million tC) as of $1995, \underline{S}=613, \beta=0.64$. Parameter $\alpha$ is allowed to vary between 0 and 1 . 
$\delta=1 / 1.1$

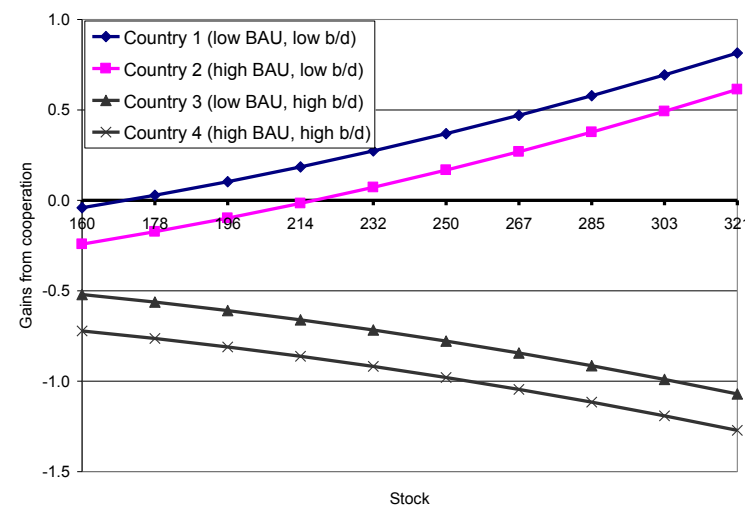

$\delta=1 / 1.025$

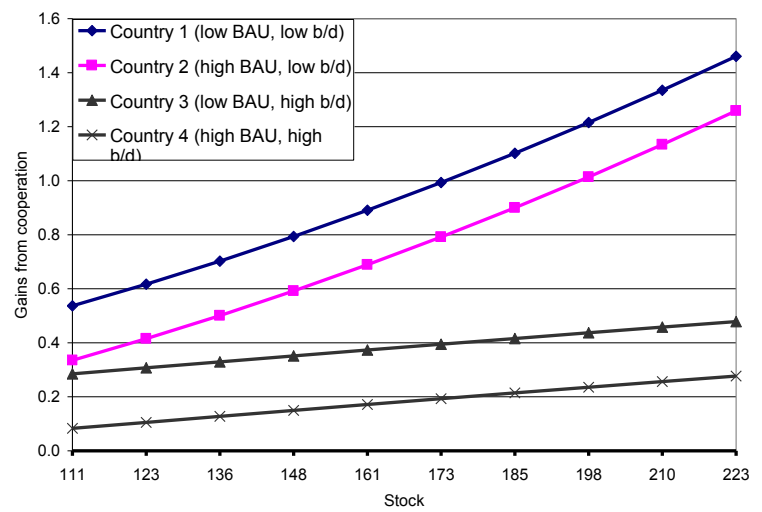

Figure 8: Gains from cooperation for heterogeneous countries. Parameter values:

$N=4, a=(10,10.2,10,10.2), b=5, d=(0.0001,0.0001,0.00008,0.00008), \lambda=0.99, \underline{S}=\beta=0$, and $z=0$. 


\section{Appendix 1}

\section{Conditions for the efficient outcome}

Suppose $T=1$. Consider countries' incentive to deviate in Phase I. In period $t$, given current stock $S_{t}$, country $j$ 's payoff upon cooperation is $V_{j}\left(S_{t}\right)$. Country $j$ 's payoff upon deviation, with over-emission $x_{j}^{D}$ in period $t$, is given by

$$
\pi_{j}\left(x_{j}^{D}, S_{t}\right)+\delta \pi_{j}\left(x_{j}^{j}\left(S_{t+1}^{\prime}\right), S_{t+1}^{\prime}\right)+\delta^{2} V_{j}\left(S_{t+2}^{\prime}\right)
$$

where $S_{t+1}{ }^{\prime}=g\left(S_{t}, x_{-j}^{j}, x_{j}^{D}\right)$ and $S_{t+2}{ }^{\prime}=g\left(S_{t+1}, x^{*}\left(S_{t+1}\right)\right)$. This is a discounted sum of a current gain by over-emitting in period $t$, a low return in period $t+1$ due to punishment, and continuation payoffs with a larger GHG stock due to its own over-emission. Therefore, no country deviates from Phase I if

$$
\begin{gathered}
V_{j}(S) \geq \pi_{j}\left(x_{j}^{D}, S\right) \\
+\delta \pi_{j}\left(x_{j}^{j}\left(g\left(S, x_{j}^{D}, x_{-j}^{*}(S)\right)\right), g\left(S, x_{j}^{D}, x_{-j}^{*}(S)\right)\right)+\delta^{2} V_{j}\left(g\left(g\left(S, x_{j}^{D}, x_{-j}^{*}(S)\right), x^{j}\left(g\left(S, x_{j}^{D}, x_{-j}^{*}(S)\right)\right)\right)\right)
\end{gathered}
$$

for all $x_{j}^{D} \geq 0, S \geq S_{0}$ and all $j$.

In Phase $\mathrm{II}_{j}$, country $j$ does not deviate from cooperation if

$$
\begin{aligned}
\pi_{j}\left(x_{j}^{j}(S), S\right)+\delta V_{j} & \left(g\left(S, x^{j}(S)\right)\right) \geq \pi_{j}\left(x_{j}^{D}, S\right)+\delta \pi_{j}\left(x_{j}^{j}\left(g\left(S, x_{j}^{D}, x_{-j}^{j}(S)\right)\right), g\left(S, x_{j}^{D}, x_{-j}^{j}(S)\right)\right) \\
+ & \delta^{2} V_{j}\left(g\left(g\left(S, x_{j}^{D}, x_{-j}^{j}(S)\right)\right), x^{j}\left(g\left(S, x_{j}^{D}, x_{-j}^{j}(S)\right)\right)\right),
\end{aligned}
$$

for all $x_{j}^{D} \geq 0$ and all possible stock levels given $S_{0}$ (i.e. for all $\left.S \geq g\left(S_{0},\left(x_{-j}^{*}\left(S_{0}\right), x_{j}^{D}\right)\right)\right)$.

Similarly, in Phase $\mathrm{II}_{k}$, country $j$ has no incentive to deviate if

$$
\begin{aligned}
\pi_{j}\left(x_{j}^{k}(S), S\right)+\delta V_{j} & \left(g\left(S, x^{k}(S)\right)\right) \geq \pi_{j}\left(x_{j}^{D}, S\right)+\delta \pi_{j}\left(x_{j}^{j}\left(g\left(S, x_{-j}^{k}, x_{j}^{D}\right)\right), g\left(S, x_{-j}^{k}, x_{j}^{D}\right)\right) \\
& +\delta^{2} V_{j}\left(g\left(g\left(S, x_{-j}^{k}, x_{j}^{D}\right), x^{j}\left(g\left(S, x_{-j}^{k}, x_{j}^{D}\right)\right)\right)\right),
\end{aligned}
$$


for all $x_{j}^{D} \geq 0$ and all $S \geq g\left(S_{0},\left(x_{-k}^{*}, x_{k}^{D}\right)\right)$.

To summarize, the strategy profile is a subgame perfect equilibrium if conditions (1), (2), and (3) (for all $k \neq j$ ) hold for all possible deviations, all $S \geq S_{0}$ and all $j$.

\section{Proof of Proposition 1}

Let $\hat{x}$ be the optimal deviation by country $i$ in phase $\mathrm{II}_{i}, v$ the optimal value function of country $i$, and $X^{*}$ the optimal total emission of $N$ countries (all of which are functions of stock $\left.S_{t}.\right)$ Let $G\left(z, S_{t}\right)$ be the gain from deviation for country $i$ in Phase $\operatorname{II}_{i}\left(S_{t}\right)$ :

$$
\begin{gathered}
G\left(z, S_{t}\right)=B(\hat{x})-D\left(S_{t}\right)+\delta\left[B(z)-D\left(S_{t+1}^{d}\right)\right\rfloor+\delta^{2} v\left(S_{t+2}^{d}\right)-\left\lfloor B(z)-D\left(S_{t}\right)+\delta v\left(S_{t+1}^{*}\right)\right\rfloor \\
=B(\hat{x})-B(z)+\delta\left[B(z)-D\left(S_{t+1}^{d}\right)\right\rfloor+\delta^{2} v\left(S_{t+2}^{d}\right)-\delta v\left(S_{t+1}^{*}\right),
\end{gathered}
$$

where $S_{t+1}^{d} \equiv \lambda S_{t}+X^{*}\left(S_{t}\right)-z+\hat{x}, S_{t+2}^{d} \equiv \lambda S_{t+1}^{d}+X^{*}\left(S_{t+1}^{d}\right)$, and $S_{t+1}^{*} \equiv \lambda S_{t}+X^{*}\left(S_{t}\right)$.

Step 1. To show $\frac{\partial G}{\partial z}=B^{\prime}(\hat{x})-(1-\delta) B^{\prime}(z)$.

The partial derivative of $G$ with respect to $z$ is given by

$$
\begin{gathered}
\frac{\partial G}{\partial z}=B^{\prime}(\hat{x}) \frac{\partial \hat{x}}{\partial z}-B^{\prime}(z)+\delta B^{\prime}(z)-\delta D^{\prime}\left(S_{t+1}^{d}\right)\left[-1+\frac{\partial \hat{x}}{\partial z}\right]+\delta^{2} v^{\prime}\left(S_{t+2}^{d}\right)\left[\lambda+X^{* \prime}\left(S_{t+1}^{d}\right)\right]\left[-1+\frac{\partial \hat{x}}{\partial z}\right] \\
=\frac{\partial \hat{x}}{\partial z}\left[B^{\prime}(\hat{x})-\delta D^{\prime}\left(S_{t+1}^{d}\right)+\delta^{2} v^{\prime}\left(S_{t+2}^{d}\right)\left[\lambda+X^{* \prime}\left(S_{t+1}^{d}\right)\right]\right. \\
-B^{\prime}(z)+\delta B^{\prime}(z)+B^{\prime}(\hat{x})-B^{\prime}(\hat{x})+\delta D^{\prime}\left(S_{t+1}^{d}\right)-\delta^{2} v^{\prime}\left(S_{t+2}^{d}\right)\left\lfloor\lambda+X^{* \prime}\left(S_{t+1}^{d}\right)\right]
\end{gathered}
$$

where the first term equals zero due to the envelope theorem. Therefore,

$$
\frac{\partial G}{\partial z}=-\left[B^{\prime}(\hat{x})-\delta D^{\prime}\left(S_{t+1}^{d}\right)+\delta^{2} v^{\prime}\left(S_{t+2}^{d}\right)\left[\lambda+X^{* \prime}\left(S_{t+1}^{d}\right)\right]+B^{\prime}(\hat{x})-(1-\delta) B^{\prime}(z) .\right.
$$


Applying the envelope theorem once again, we have

$$
\frac{\partial G}{\partial z}=B^{\prime}(\hat{x})-(1-\delta) B^{\prime}(z)
$$

Let $\hat{x}_{I}\left(S_{t}\right)$ be the optimal deviation by country $i$ in phase $\mathrm{I}\left(S_{t}\right)$ and $G_{I}\left(z, S_{t}\right)$ the gain from deviation for country $i$ in Phase $\mathrm{I}\left(S_{t}\right)$ :

$$
\begin{aligned}
G_{I}\left(z, S_{t}\right)= & B\left(\hat{x}_{I}\right)-D\left(S_{t}\right)+\delta\left[B(z)-D\left(S_{t+1}^{d, I}\right)\right\rfloor+\delta^{2} v\left(S_{t+2}^{d, I}\right)-\left\lfloor B\left(x^{*}\right)-D\left(S_{t}\right)+\delta v\left(S_{t+1}^{*}\right)\right\rfloor \\
& =B\left(\hat{x}_{I}\right)-B\left(x^{*}\right)+\delta\left[B(z)-D\left(S_{t+1}^{d, I}\right)\right\rfloor+\delta^{2} v\left(S_{t+2}^{d, I}\right)-\delta v\left(S_{t+1}^{*}\right),
\end{aligned}
$$

where $S_{t+1}^{d, I} \equiv \lambda S_{t}+X^{*}\left(S_{t}\right)-x^{*}\left(S_{t}\right)+\hat{x}_{I}, S_{t+2}^{d, I} \equiv \lambda S_{t+1}^{d}+X^{*}\left(S_{t+1}^{d}\right)$, and $S_{t+1}^{*} \equiv \lambda S_{t}+X^{*}\left(S_{t}\right)$.

Step 2. To show $\frac{\partial G_{I}}{\partial z}=\delta B^{\prime}(z)$

The partial derivative of $G$ with respect to $z$ is given by

$$
\begin{aligned}
\frac{\partial G_{I}}{\partial z}= & B^{\prime}\left(\hat{x}_{I}\right) \frac{\partial \hat{x}_{I}}{\partial z}+\delta B^{\prime}(z)-\delta D^{\prime}\left(S_{t+1}^{d}\right) \frac{\partial \hat{x}_{I}}{\partial z}+\delta^{2} v^{\prime}\left(S_{t+2}^{d}\right)\left[\lambda+X^{* \prime}\left(S_{t+1}^{d}\right)\right] \frac{\partial \hat{x}_{I}}{\partial z} \\
= & \frac{\partial \hat{x}_{I}}{\partial z}\left[B^{\prime}\left(\hat{x}_{I}\right)-\delta D^{\prime}\left(S_{t+1}^{d}\right)+\delta^{2} v^{\prime}\left(S_{t+2}^{d}\right)\right]+\delta B^{\prime}(z)=\delta B^{\prime}(z),
\end{aligned}
$$

where the last equality follows from the envelope theorem.

Step 3. To show $G(z, S) \geq G_{I}(z, S)$ for all $S$.

Note that $G\left(x^{*}(S), S\right)-G_{I}\left(x^{*}(S), S\right)=0$, i.e. the gains from deviation are the same in Phases I and II when $z$ equals $x^{*}(S)$. Steps 1 and 2 imply

$$
\frac{\partial}{\partial z}\left[G(z, S)-G_{I}(z, S)\right]=B^{\prime}(\hat{x})<0
$$

for all $z \in\left[0, x^{*}(S)\right]$ given any stock level as long as $\hat{x}>z$. It follows from the last two equations that $G \geq G_{I}$ for all $z$. Hence, condition (2) implies condition (1). A similar argument proves that condition (2) implies condition (3). 


\section{Proof of Proposition 2}

Let $T \geq 2$. Suppose that, for any $S \in\left[S_{0}, S^{*}\right]$, cooperating in Phase II $_{j}(S)$ is preferred to optimal deviation in the first period in the phase:

$$
\begin{gathered}
B(z)-D(S)+\delta\left[B(z)-D\left(S_{1}\right)\right]+\ldots+\delta^{T-1}\left[B(z)-D\left(S_{T-1}\right)\right]+\delta^{T} v\left(S_{T}\right) \\
\geq B\left(\hat{x}_{1}\right)-D(S)+\delta\left[B(z)-D\left(S_{1}^{1}\right)\right]+\delta^{2}\left[B(z)-D\left(S_{2}^{1}\right)\right]+\ldots+\delta^{T}\left[B(z)-D\left(S_{T}^{1}\right)\right]+\delta^{T+1} v\left(S_{T+1}^{1}\right),
\end{gathered}
$$

where $S_{1}=g\left(S, X^{*}(S)\right), S_{2}=g\left(S_{1}, X^{*}\left(S_{1}\right)\right), S_{1}^{1}=g\left(S, X_{-j}^{*}(S)+\hat{x}_{1}\right), S_{2}^{1}=g\left(S_{1}^{1}, X^{*}\left(S_{1}^{1}\right)\right)$, and so

on. The payoff upon deviating in the second period in the phase is given by

$$
\begin{aligned}
& B(z)-D(S)+\delta\left[B\left(\hat{x}_{2}\right)-D\left(S_{1}\right)\right]+\delta^{2}\left[B(z)-D\left(S_{2}^{2}\right)\right]+\ldots+\delta^{T+1}\left[B(z)-D\left(S_{T+1}^{2}\right)\right]+\delta^{T+2} v\left(S_{T+2}^{2}\right) \\
& \leq B(z)-D(S)+\delta\left\{B(z)-D\left(S_{1}\right)+\delta\left[B(z)-D\left(S_{2}\right)\right]+\ldots+\delta^{T-1}\left[B(z)-D\left(S_{T}\right)\right]+\delta^{T} v\left(S_{T+1}\right)\right\}
\end{aligned}
$$

where $S_{2}^{2}=g\left(S, X_{-j}^{*}(S)+\hat{x}_{2}\right), S_{3}^{2}=g\left(S_{2}^{2}, X^{*}\left(S_{2}^{2}\right)\right)$, and so on. The inequality follows because

the first inequality above holds for $S_{1} \in\left[S_{0}, S^{*}\right]$. Now the last expression would correspond to the payoff upon cooperating in phase II ${ }_{j}$ if phase II lasted for $T+1$ periods. Because the continuation payoff for country $j$ in phase $\mathrm{II}_{j}$ is decreasing in the number of periods it lasts $(T)$, it follows that the last expression does not exceed the payoff upon cooperation in phase II $_{j}$ when it lasts for $T$ periods:

$$
B(z)-D(S)+\delta\left[B(z)-D\left(S_{1}\right)\right]+\ldots+\delta^{T-1}\left[B(z)-D\left(S_{T-1}\right)\right]+\delta^{T} v\left(S_{T}\right)
$$

That is, if the first-period deviation does not improve country $j$ 's payoff in phase $\mathrm{II}_{j}$, then the second-period deviation does not improve it either. The same logic applies as we compare the payoffs upon optimal deviation in the first period with those in the third or later periods. Therefore, for phase II ${ }_{j}$ to be self-enforcing, it is sufficient to verify that the payoff upon 
cooperation in phase $\mathrm{II}_{j}$ is greater than or equal to the payoff upon optimal deviation when deviation occurs in the first period of phase $\mathrm{II}_{j}$. 


\section{Appendix 2 Assumptions of the climate change exercise}

Several studies have used quadratic models to approximate the global benefit and damage functions (Falk and Mendelsohn 1993, List and Mason 2001, Newell and Pizer 2003, Karp and Zhang 2005, 2006). We combine these models with an estimate of regional benefits and damages by Nordhaus and Yang (1996) and Nordhaus and Boyer (2000).

We assume that country $i$ 's emission benefit and the climate damage in period $t$ are both functions of $y_{i t}$, the country's GDP in period $t$ :

$$
\left\{\hat{a}_{i} x_{i t}-\hat{b}_{i} x_{i t}^{2}\right\} y_{i t}-\left\{\hat{c}_{i} S_{t}+\hat{d}_{i} S^{2}+\hat{f}_{i}\right\} y_{i t}
$$

e also assume that country $i$ 's population growth rate is $n_{i}>0$ and the growth rate of GDP per capita is $g_{i}>0$; both these rates are constant over time. If the country's consumption discount rate is $r_{i}>0$, then country $i$ 's present-value return is given by

$$
\begin{gathered}
\sum_{t=o}^{\infty}\left(\frac{1}{1+r_{i}}\right)^{t} \cdot\left(1+n_{i}\right)^{t}\left(1+g_{i}\right)^{t} y_{i 0}\left\{\hat{a}_{i} x_{i t}-\hat{b}_{i} x_{i t}^{2}-\left(\hat{c}_{i} S_{t}+\hat{d}_{i} S^{2}+\hat{f}_{i}\right)\right\} \\
=\sum_{t=o}^{\infty} \delta_{i}^{t} y_{i 0}\left\{\hat{a}_{i} x_{i t}-\hat{b}_{i} x_{i t}^{2}-\left(\hat{c}_{i} S_{t}+\hat{d}_{i} S^{2}+\hat{f}_{i}\right)\right\}, \\
=\sum_{t=o}^{\infty} \delta_{i}^{t}\left\{a_{i} x_{i t}-b_{i} x_{i t}^{2}-\left(c_{i} S_{t}+d_{i} S^{2}+f_{i}\right)\right\},
\end{gathered}
$$

where $\delta_{i} \equiv \frac{\left(1+n_{i}\right)\left(1+g_{i}\right)}{1+r_{i}}, a_{i} \equiv y_{i 0} \hat{a}_{i}, b_{i} \equiv y_{i 0} \hat{b}_{i}, d_{i} \equiv y_{i 0} \hat{d}_{i}$, and so on. In this simulation, we assume that the benefit and damage functions are time-invariant except for changes due to GDP and population growth. We also assume that all countries' composite discount factors are identical: $\delta_{i}=\delta$ for all $i$. A time period corresponds to one year. We model the emissions and accumulation of $\mathrm{CO}_{2}$ and do not consider other GHGs. 


\section{Benefit functions}

We specify the benefit functions using the following functional form:

$$
B_{i}\left(x_{i}\right)=-\frac{\left(\bar{e}_{i}-x_{i}\right)^{2}}{2 \theta_{i}} y_{i t}=\left\{\frac{1}{2 \theta_{i}} x_{i}-\frac{\bar{e}_{i}}{\theta_{i}} x_{i}^{2}-\frac{\bar{e}_{i}^{2}}{2 \theta_{i}}\right\} y_{i t},
$$

where $\bar{e}_{i}>0$ represents country $i$ 's myopic BAU emission and $y_{i t}$ the regional GDP. The value $1 / \theta_{i}$ represents the slope of the marginal cost of emission reduction (in terms of $\%$ of GDP) for country $i$. This specification allows us to aggregate the benefit functions to derive the global benefit in a simple way. A function $B$ where $B(X) \equiv-\frac{(\bar{E}-X)^{2}}{2 \Theta}$ with $\bar{E}=\sum_{i} \bar{e}_{i}$ and $\Theta \equiv \sum_{i}\left(\theta_{i} / y_{i 0}\right)$ satisfies

$$
B(X)=\max _{\left\{x_{i}\right\}}\left\{\sum_{i}-\frac{\left(\bar{e}_{i}-x_{i}\right)^{2}}{2 \theta_{i}} \mid \sum_{i} x_{i}=X\right\}
$$

This function $B$ represents the global net benefit function. We chose the values of $\left\{\bar{e}_{i}\right\}$ to be equal to the $\mathrm{CO}_{2}$ emissions from the corresponding regions in the year 1995. Nordhaus and Yang (1996) use an estimate of $\left\{B_{i}(0) / y_{i 0}\right\}$, the fraction of annual GDP required to reduce net $\mathrm{CO} 2$ emissions to 0 in each region:

$$
B_{i}(0) / y_{i 0}=\frac{\bar{e}_{i}^{2}}{2 \theta_{i}}
$$

We can pin down the value of the parameters $\theta_{i}, a_{i}, b_{i}$, and a constant term $f_{1 i}$ using the estimates of the right-hand side and $\bar{e}_{i}$ :

$$
a_{i}=y_{i 0} \cdot \frac{1}{2 \theta_{i}}, b_{i}=y_{i 0} \cdot \frac{\bar{e}_{i}}{\theta_{i}}, f_{1 i}=y_{i 0} \cdot \frac{\bar{e}_{i}^{2}}{2 \theta_{i}}
$$

Table A-1 summarizes the regional aggregates assumed for our simulation. Figure 4-1 draws the 
regional marginal abatement costs of $\mathrm{CO} 2$ emissions. While the marginal abatement costs are relatively high in Japan and Europe, they are lower in US, Russia, and China. The relative ranking of MAC across regions agrees with the estimates in existing studies. Figure 4-2, which lists the marginal abatement cost estimate by Ellerman and Decaux (1998), shows a very similar ranking of MACs.

\section{Damage functions}

We specify the following functional form for the damage functions.

$$
D_{i}\left(S_{t}\right)=y_{i t}\left\{d_{i}\left(S_{t}-\underline{S}\right)^{2}+c_{i}\left(S_{t}-\underline{S}\right)+f_{2 i}\right\}
$$

Nordhaus (1998) estimates the regional damages, in terms of a fraction of regional GDP, as a function of changes in the average atmospheric temperature relative to the preindustrial level:

$$
D_{i}^{T}(T)=d_{1 i} T+d_{2 i} T^{2}
$$

He derives the values of the parameters $\left\{d_{1 i}, d_{2 i}\right\}$ by calibrating the above function to the point estimates of damages at 2.5 and 6 mean temperature increases (see Table 4-1). Following Kattenberg et al (1996) and Newell and Pizer (2003), assume that temperature change is proportional to the change in the log of the carbon stock. ${ }^{16}$ We pin down the $\mathrm{CO} 2$ stock level corresponding to a 2.5 increase by using this log relationship: This implies that the carbon stock level associated with 2.5 warming is

$$
S_{2.5}=e^{(2.5+2.885 \ln (\underline{S})) / 2.885} \approx 1,458 G t C .
$$

\footnotetext{
${ }^{16}$ Specifically, let $T(S)$ be the increase in temperature, relative to the preindustrial level, associated with the $\mathrm{CO}_{2}$ concentration $S$. Then

$$
T(S) \approx 2.885 \ln \left(\frac{S}{S}\right) .
$$
}


Since we assume a linear-quadratic damage as a function of $\mathrm{CO} 2$ stock, we apply linear interpolation to identify the damage function parameters:

$$
\begin{gathered}
D_{i}(S)=d_{i 1}(T(S))+d_{i 2}(T(S))^{2}=d_{i 1}(t(S-\underline{S}))+d_{i 2}(t(S-\underline{S}))^{2} \\
=d_{i 1} t S-d_{i 1} t \underline{S}+d_{i 2} t^{2}\left(S^{2}-2 \underline{S} S+\underline{S}^{2}\right)=S^{2}\left(d_{i 2} t^{2}\right)+S\left(d_{i 1} t-2 \underline{S} d_{i 2} t^{2}\right)-d_{i 1} t \underline{S}+d_{i 2} t^{2} \underline{S}^{2} .
\end{gathered}
$$

We pin down the value of $t$ by plugging in $D_{i}\left(S_{2.5}\right)=D_{i}^{T}(2.5)$ and $S=S_{2.5}$. Once $t$ is identified, we can find the values of the damage function parameters:

$$
d_{i}=d_{i 2} t^{2}, c_{i}=d_{i 1} t-2 \underline{S} d_{i 2} t^{2}, f_{i}=-d_{i 1} t \underline{S}+d_{i 2} t^{2} \underline{S}^{2} .
$$

The constant term is identified by $f_{i}=f_{1 i}+f_{2 i}$.

Figure A-3 represents the damage as $\%$ of regional GDP for each region. According to Nordhaus's estimates, India, Europe, and Africa are more vulnerable to climate change than US, China, and Russia. Some countries including Russia are expected to experience positive climate benefits for a modest increase in the $\mathrm{CO} 2$ stock.

With the above assumptions, the ratio $B / D$ based on Nordhaus and Boyer's model (2000) is

$$
\frac{B}{D} \approx \frac{32.3827}{6.0195 \times 10^{-4}} \approx 53,630
$$

Table A-2 summarizes the estimates of $\gamma$ used in the literature. Karp and Zhang (2009) applied a point estimate of $B=26.992$ and $D=0.0022$. Newell and Pizer (2003) applied a point estimate of $B=1.60^{*} 10^{-7}$ and $D=8.70 * 10^{-13} \cdot{ }^{17}$ Hoel and Karp (2002) is a point estimate as discussed in Karp and Zhang (2005). Hoel and Karp (2002) report the above estimates used in Falk and Mendelsohn (1993) and Reilly (2002).

\footnotetext{
${ }^{17}$ Newell and Pizer (2003) assume that $B$ and $D$ grow at different rates, and consider a range of growth rates for their sensitivity analysis.
} 
Table A-1: Data used for simulation.

\begin{tabular}{lccccc}
\hline & (A) & (B) & (C) & (D) & (E) \\
& GDP & CO2 & & & \\
& $(1995)$ & $(1995)$ & $\mathrm{d} 1$ & $\mathrm{~d} 2$ & $\mathrm{C}$ \\
\hline Europe & 6,892 & 0.851 & -0.00095 & 0.00491 & 0.05 \\
USA & 6,176 & 1.407 & -0.00257 & 0.00174 & 0.07 \\
Japan & 3,420 & 0.308 & -0.00418 & 0.00247 & 0.05 \\
LMI (lower-middle income & & & & & \\
countries) & 1,156 & 0.561 & 0.00223 & 0.00255 & 0.10 \\
MI (middle-income countries) & 1,138 & 0.298 & 0.00390 & 0.00134 & 0.10 \\
OHI (other high-income) & 1,087 & 0.249 & -0.01079 & 0.00369 & 0.05 \\
China & 654 & 0.871 & -0.00414 & 0.00201 & 0.15 \\
LI (low-income countries) & 570 & 0.327 & 0.00628 & 0.00249 & 0.10 \\
India & 447 & 0.248 & 0.00741 & 0.00492 & 0.10 \\
EE (Eastern Europe) & 380 & 0.368 & -0.00516 & 0.00187 & 0.15 \\
Russia & 334 & 0.496 & -0.01078 & 0.00327 & 0.15 \\
HIO (high-income OPEC) & 234 & 0.129 & 0.00412 & 0.00148 & 0.10 \\
Africa & 199 & 0.045 & 0.01560 & 0.00097 & 0.10 \\
World & 22,687 & 6.159 & 0.00071 & 0.00270 & 0.07 \\
\hline
\end{tabular}

Note: (A), (B): Nordhaus and Boyer (2000), Table 3.2, p. 39. (C) (D): Nordhaus 1998 Table 12, (E): Nordhaus and Yang (1996), Table 2, p.746. (A) is measured in billion 1990 US GDP with market exchange rates and (B) in billion metric tons of carbon equivalent. Parameters $\mathrm{d} 1, \mathrm{~d} 2$ are damage function parameters such that $\mathrm{d} 1 * \mathrm{~T}+\mathrm{d} 2 * \mathrm{~T}^{2}$ represents regional damage (percentage of regional GDP) when temperature increase is given by T. $\mathrm{C} 1$ is an abatement cost function parameter and represents the fraction of annual output required to reduce net $\mathrm{CO} 2$ emissions to 0 .

Table A-2: Estimates of $\gamma$ in previous studies.

\begin{tabular}{lr}
\hline Study & \multicolumn{1}{c}{$\gamma$} \\
\hline Karp and Zhang (2009) & 12,269 \\
Newell and Pizer (2003) & 183,908 \\
Nordhaus and Boyer (2000) & 53,630 \\
Hoel and Karp (2002)'s point estimate & 71,114 \\
FM as discussed in HK (2002) & 72,993 \\
Reilly as discussed in HK (2002) & 50,000 \\
\hline
\end{tabular}

